\title{
Approaches to Sustainability in Chemical Mechanical Polishing (CMP): A Review
}

\author{
Hyunseop Lee ${ }^{1} \mathbb{D} \cdot$ Hyoungjae $\mathrm{Kim}^{2} \cdot$ Haedo Jeong $^{3}$
}

Received: 20 May 2021 / Revised: 9 September 2021 / Accepted: 6 November 2021 / Published online: 26 November 2021

(c) Korean Society for Precision Engineering 2021

\begin{abstract}
Chemical mechanical polishing (CMP) is an essential planarization process for semiconductor manufacturing. The application of CMP has been increasing in semiconductor fabrication for highly integrated devices. Recently, environmental burden caused by the CMP process was assessed because of interest in the global environment. In this study, the previously reported impacts of CMP on the environment and studies conducted on developing various methods to reduce environmental burden are reviewed. In addition to analyzing the impacts of CMP, this paper introduces a method for treating CMP wastewater and improving the material removal efficiency through the improvement of CMP consumables. Finally, the authors review research on hybridization of the CMP process and discuss the direction in which CMP technology will progress to improve sustainability in the future.
\end{abstract}

Keywords Chemical mechanical polishing (CMP) $\cdot$ Sustainability $\cdot$ Slurry $\cdot$ Polishing pad $\cdot$ Hybrid CMP system

\section{Introduction}

Chemical mechanical polishing (CMP) uses chemical reactions and mechanical forces for material removal [1-3]. Although CMP is a planarization method that uses particles that can cause killer deflect such as a scratch, it has the longest planarization length, compared to existing planarization processes, making it essential for device fabrication. The basic mechanism of the CMP process is the mechanical removal of the chemically softened material surface [4, 5]. Figure 1 shows a schematic of the CMP process and material removal mechanism. The wafer and polishing pad are attached underside of the carrier and on the platen,

This paper is an invited paper (Invited Review).

Hyunseop Lee

hyunseop@dau.ac.kr

1 Department of Mechanical Engineering, Dong-A University, 37 Nakdong-daero 550beon-gil, Saha-gu, Busan 49315 , Republic of Korea

2 Korea Institute of Industrial Technology, 42-7 Baehyang-daero 804beon-gil, Sasang-gu, Busan 46938, Republic of Korea

3 School of Mechanical Engineering, Pusan National University, 2 Busandaehak-ro 63beon-gil, Geumjeong-gu, Busan 46241, Republic of Korea respectively. A slurry containing abrasive particles and chemicals is supplied over the polishing pad. The polishing head presses the wafer on the pad's surface. The wafer and polishing pad are rotated counterclockwise, as a result of which the slurry enters the interface between them. Pad conditioning is performed using a diamond disk to clean and control the pad surface [6].

CMP is used for global planarization of surfaces in semiconductor manufacturing, such as shallow wrench (STI) isolation [7, 8], planarization of inter-layer dielectric (ILD) [9], formation of tungsten (W) contact [10,11], and formation of metal wiring [12]. The associated market is growing significantly as the demand for faster and better electronic equipment such as smartphones and artificial intelligence devices, increases. The main factors contributing to the evaluation [13] of the CMP results are as follows.

(a) Material removal rate (MRR)

(b) Within-wafer non-uniformity (WIWNU)

(c) Wafer-to-wafer non-uniformity (WTWNU)

(d) Chemical and physical defects

For a long time, CMP engineers and users have been working to obtain uniform and high MRRs and defect-free surfaces for planarizing various materials. Lee and Sung [14] summarized the research topics related to CMP over the 


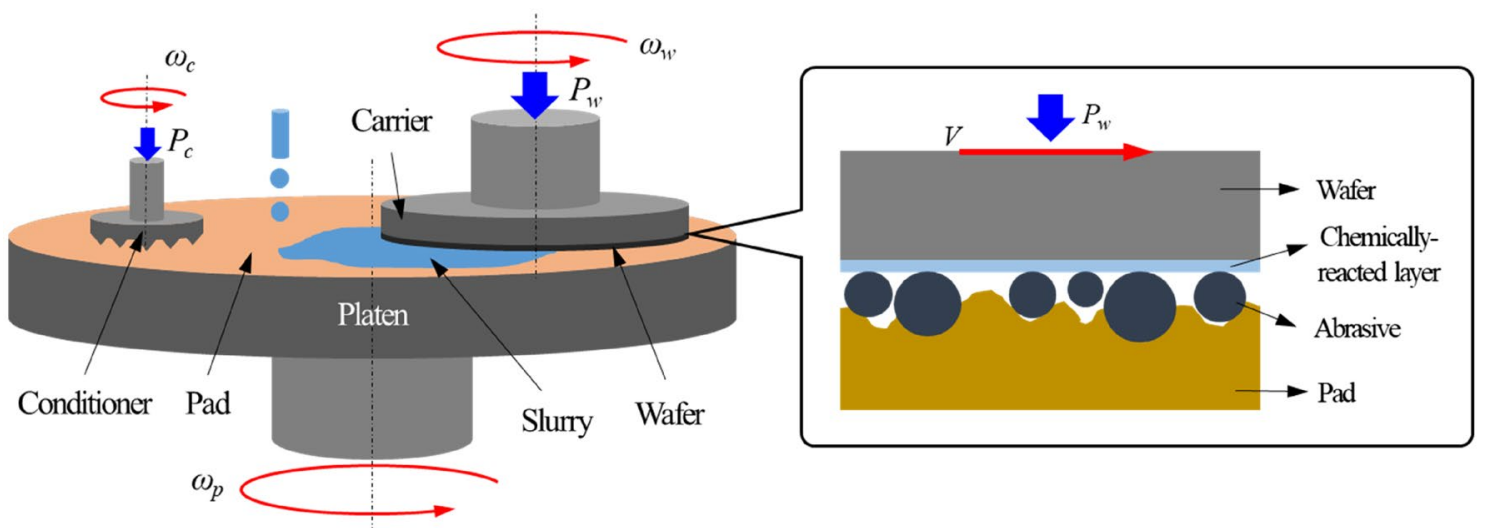

Fig. 1 Schematic of CMP process and material removal mechanism

last 5 years in Elsevier DB and Springer DB (243 papers in 64 journals) (Fig. 2). Of the total studies, about $71.2 \%$ of the studies are on process analysis and chemical and mechanical effects, and most of the studies consist of understanding the mechanisms of material removal and improving CMP efficiency. However, recent changes in global climate environment has increased the interest in sustainability of the semiconductor and CMP industries. Academics are also conducting research on various methods to assess the impact of semiconductor processes on the environment and reduce the environmental burden. Further, the interest in improving process efficiency for reducing energy consumption in the semiconductor processes is increasing.

In this paper, we review the impacts of the CMP process on the environment and various research results to improve sustainability and discuss the future of CMP technology development. This paper analyzes the environmental impact of the CMP process and summarizes the development of
CMP slurry and slurry injection systems, abrasive pads, and the hybridization of the CMP process.

\section{Environmental Burden Caused by CMP}

Efforts have been made in the semiconductor industry to reduce greenhouse gase (GHG) emissions since the ratification of the Kyoto Protocol in 2005. To reduce the emission of GHGs in semiconductor processes, researches on the environmental impact of unit processes are needed. Although there have been various studies on the environmental burden caused by semiconductor production, studies on the environmental burden caused by the CMP process are limited. In the CMP and Post-CMP cleaning processes, various chemical solutions and materials are used as consumables for slurry, cleaning solution, polishing pad, conditioner, etc. CMP consumables are manufactured from raw

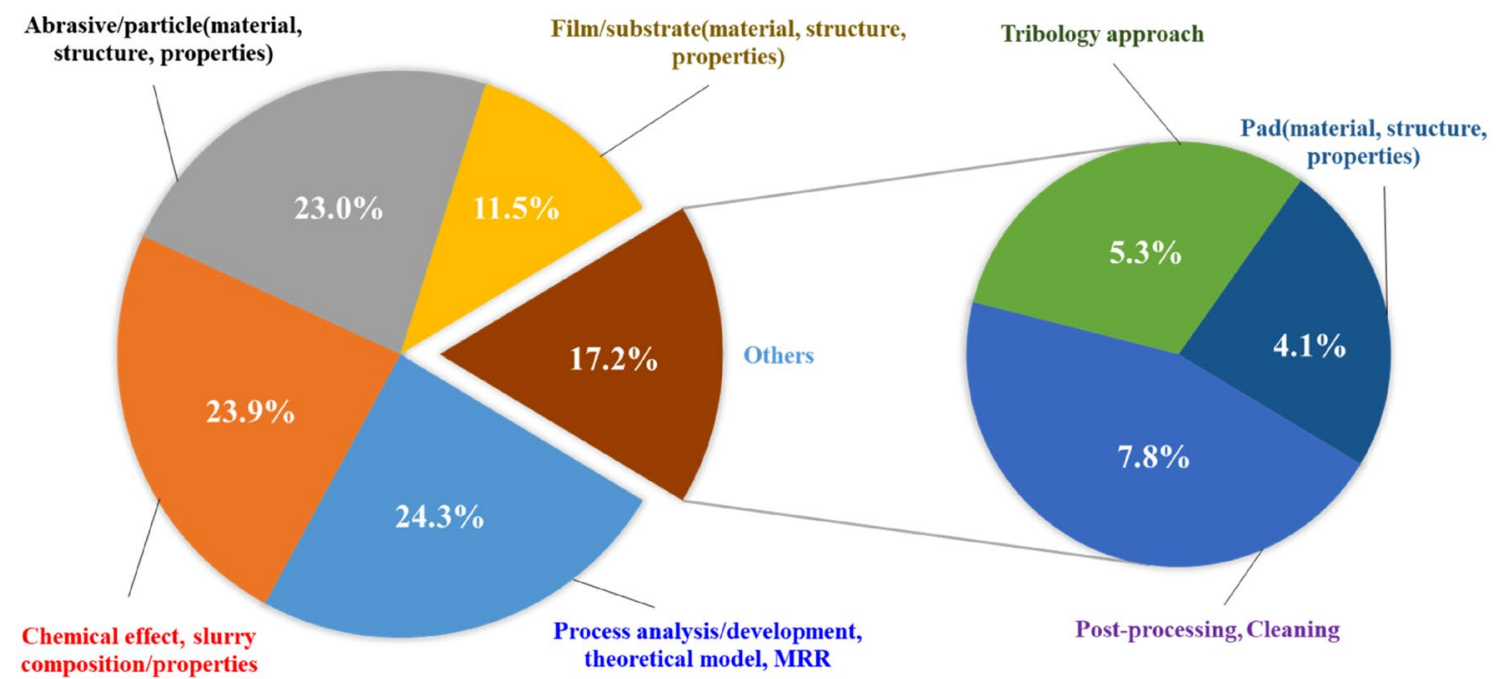

Fig. 2 CMP research topics and papers published in major academic journals (Redrawn and modified figures of reference 14) [14] 
materials and transported to chipmakers through various means of transportation. Consumables for CMP are supplied from manufacturers to semiconductor fab, most of which cannot be reused after CMP. Water and electricity are used in the production of consumables and semiconductor chips. In particular, the CMP process is known to use a significant amount of water in the semiconductor industry. Figure 3 shows the schematic of materials and energy flow for CMP and CMP consumable.

In the study of life cycle assessment (LCA) in semiconductor production, analyzing the CMP process is primarily concerned with electric energy consumption and ultrapure water (UPW) consumption. Krishnan et al. [15] assessed the environmental impacts caused by the interconnect process of fabricating a logic device (130 nm node with eight layers of copper wiring) using environmental toxicology and chemistry (SETAC) and economic input-output LCA (EIOLCA) [16]. They evaluated that CMP uses a large amount of facility water and generates abundant liquid waste. In their study, the overall energy consumption in the semiconductor process, excluding infrastructure, was assessed at 406 $\mathrm{kWh} /$ wafer. However, they did not report the environmental burden caused by the CMP process.

Murphy et al. [17] reported the power requirements for semiconductor fabrication. In their study, the power requirement for the CMP process in microprocessor wafer fab was $29 \mathrm{~kW}$ during the process and $8 \mathrm{~kW}$ when idle. In the manufacturing process of eight- and six-layer metal microprocessors, CMP is applied 18 times and 14 times, respectively, and one wafer per run and 25 wafers per hour are processed. In the semiconductor manufacturing process using $200 \mathrm{~mm}$ wafers, the eight- and six-metal layer devices require 406 $\mathrm{kWh} /$ wafer and $336 \mathrm{kWh} /$ wafer of energy, respectively. Although their research does not provide an accurate value of the energy required for CMP, their report indicates that approximately $20 \mathrm{kWh} /$ wafer would be sufficient. Their research did not consider the energy required for infrastructure, but showed that CMP accounts for approximately 5-6\% of the total energy requirement for the semiconductor process. According to Krishnan's research [18], considering the energy required for the facilities relating to semiconductor production, the energy consumed by the CMP is less than $1 \%$ of the total energy requirement. According to research results, the energy consumption of CMP in semiconductor processes has various results depending on the type of chips applied, the number of CMP processes, and the area of production.

However, as CMP uses a large amount of water and slurry containing chemicals, various elements that are consumed during the CMP process must be considered to assess the environmental burden. In particular, CMP accounts for approximately $40 \%$ of water consumption in the semiconductor industry $[19,20]$. In addition, CMP generates 30-50 L of waste slurry per $200 \mathrm{~mm}$ wafer [19, 21]. After CMP, the wastewater containing water, various chemicals, and slurry particles is disposed of after removing the particles through electrodecantation and electrocoagulation. Details of the CMP wastewater treatment are described in Chapter 3.

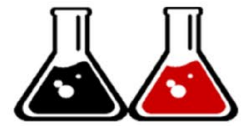

Raw chemicals (liquid, gas)

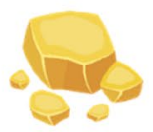

Raw materials (abrasive, polyurethane...)

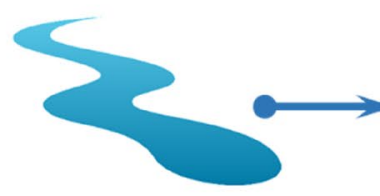

River (water)

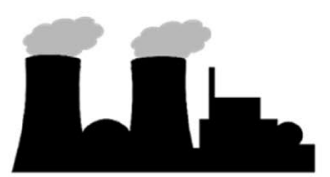

Power plant (electricity)

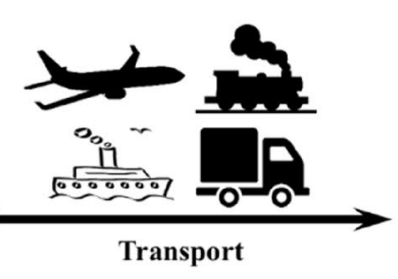

Transport

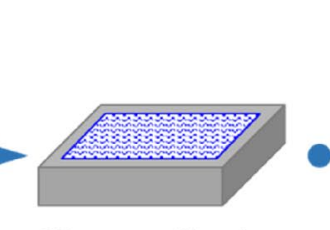

Water purification facility

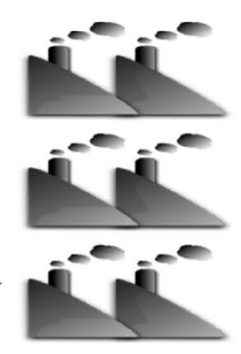

Consumable manufacturer

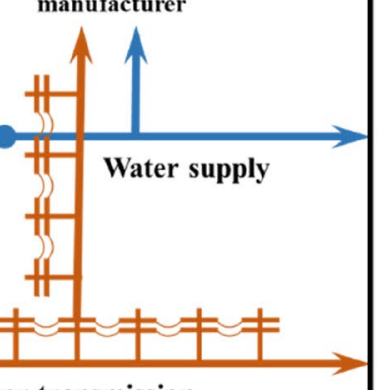

Electric power transmission

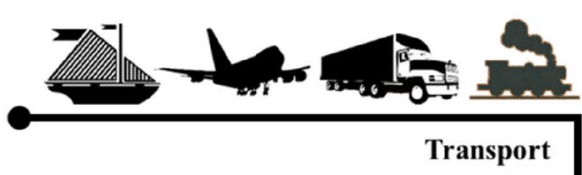

Transport
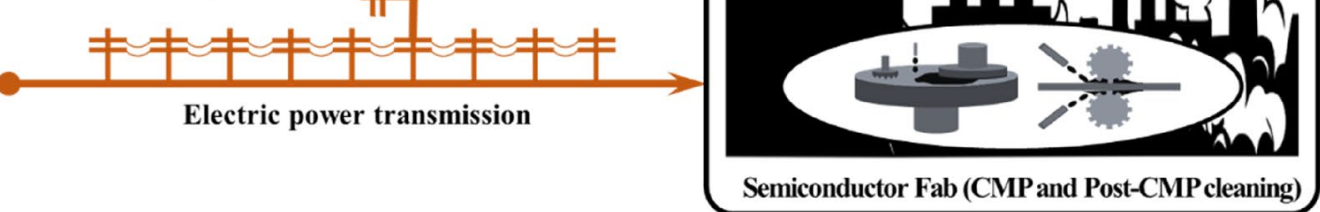

Fig. 3 Schematic of materials and energy flow for CMP and CMP consumable 


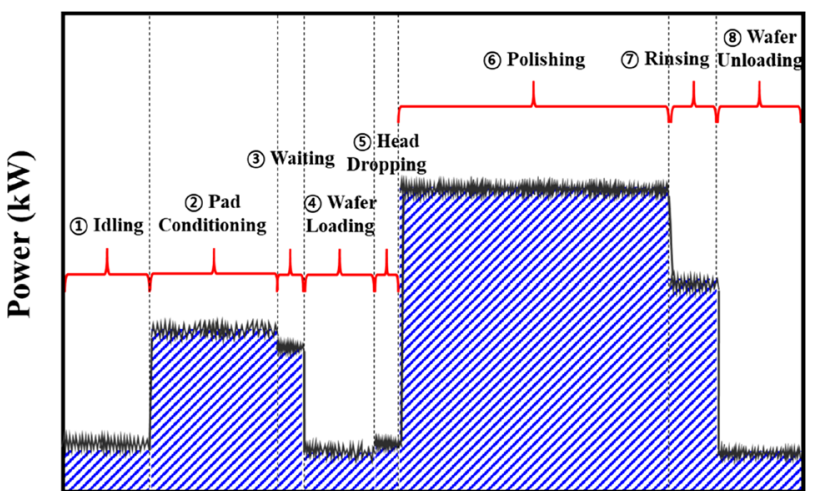

Process time (sec)

Fig. 4 Power input at CMP polisher main connection over process time and operation steps (Redrawn and modified figures of reference 22) $[22]$

Lee et al. [22] studied the environmental burden caused by CMP, including the effects of using electrical energy, UPW, and slurry in the $\mathrm{SiO}_{2} \mathrm{CMP}$ process. They considered the various steps in the CMP process, such as idling, conditioning, getting, wafer loading, head dropping, polishing, rinsing, and wafer loading, and measured the electrical energy, slurry, and UPW consumption used for each step (Fig. 4). Reportedly, under the same pressure condition, the power demand $(\mathrm{kW})$ increases linearly with an increase in the relative velocity, showing a linear relationship with the MRR. The GHG emission index for electricity used in South Korea [23] was used to convert the electric energy consumption into GHG emissions, such as $\mathrm{CO}_{2}, \mathrm{CH}_{4}, \mathrm{~N}_{2} \mathrm{O}$, and carbon dioxide equivalent ( $\mathrm{CDE}, \mathrm{CO}_{2}$-eq). In addition, the equivalent $\mathrm{CO}_{2}$ generation for the gases generated by $\mathrm{SiO}_{2} \mathrm{CMP}$ was calculated by removing the film of the target thickness using the electrical energy consumption measured through the experiment and carbon intensity of UPW purification and slurry reported in the existing study, as shown in Fig. 5. According to Passmann and Joergensen [24], UPW purification requires $0.022 \mathrm{Wh} / \mathrm{ml}$ of electrical energy. According to the chemical LCA data source provided by Boyd et al. [25], referring to Kim and Overcash's gate-to-gate LCA [26], the $\mathrm{CDE}$ generated while using the oxide CMP slurry is 0.2704 $\mathrm{gCO}_{2}-\mathrm{eq} / \mathrm{ml}$.

Lee et al. [27] proposed a mathematical model-based evaluation methodology to develop a CMP model based on the mechanical contact [28] and kinematic models [29, 30] for analyzing the environmental burden caused by CMP. They classified the consumables in the CMP as long lifespan CMP countable and short lifespan CMP countable and defined them as follows.

(a) Long lifespan CMP consumables: consumables that are replaced after using for a certain period in the CMP

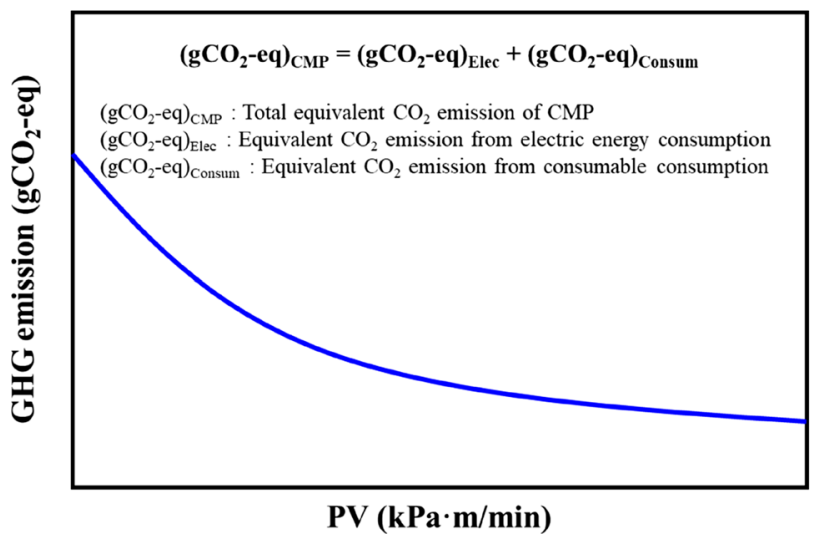

Fig. 5 Equivalent GHG emissions associated with electric energy and consumable consumptions as a function of PV (Redrawn and modified figures of reference 22) [22]

process, such as polishing pads, conditioners, retaining rings, and backing films.

(b) Short lifespan CMP consumables: consumables that are discarded after being used only one time in a CMP process, such as CMP slurry and UPW.

Lee et al. [27] proposed the environmental burden assessment method to obtain the process time required to remove the targeted film thickness through the MRR model. Then, the electrical energy consumption, slurry consumption, and UPW consumption during the process time are calculated and converted to CDE (Fig. 6). In their study, the environmental burden caused by CMP may have been underestimated compared to that measured in the industry because they used a CMP machine with a single platen (CMP machine for R\&D).

Previous studies have shown that the use of slurry in CMP must be reduced to decrease the significant environmental burden caused by it. However, the chemical composition of CMP slurry depends on the material to be removed, which changes the environmental burden depending on the slurry component. Few studies have reported on the environmental burden caused by changes in the slurry components. Lee [31] assessed the environmental burden caused by CMPs when hydrogen peroxide $\left(\mathrm{H}_{2} \mathrm{O}_{2}\right)$, citric acid $\left(\mathrm{C}_{6} \mathrm{H}_{8} \mathrm{O}_{7}\right)$, benzotriazole (BTA; $\mathrm{C}_{6} \mathrm{H}_{5} \mathrm{~N}_{3}$ ), and abrasive particle concentration change in copper CMP slurry. They used $\mathrm{H}_{2} \mathrm{O}_{2}$ as an oxidizer, citric acid as a chelating agent, and BTA as a corrosion inhibitor. They evaluated the CDE of CMP based on the following expression [31].

$C D E_{\text {cycle }}=C D E_{e}+C D E_{s}+C D E_{U}+C D E_{e t c}$

where $C D E_{e}$ refers to the CDEs of electric energy consumption, including the pad conditioning and polishing steps. 
Fig. 6 Mathematical modelbased evaluation methodology proposed by Lee et al. [27] for environmental burden caused by CMP (Redrawn and modified figures of reference 27)

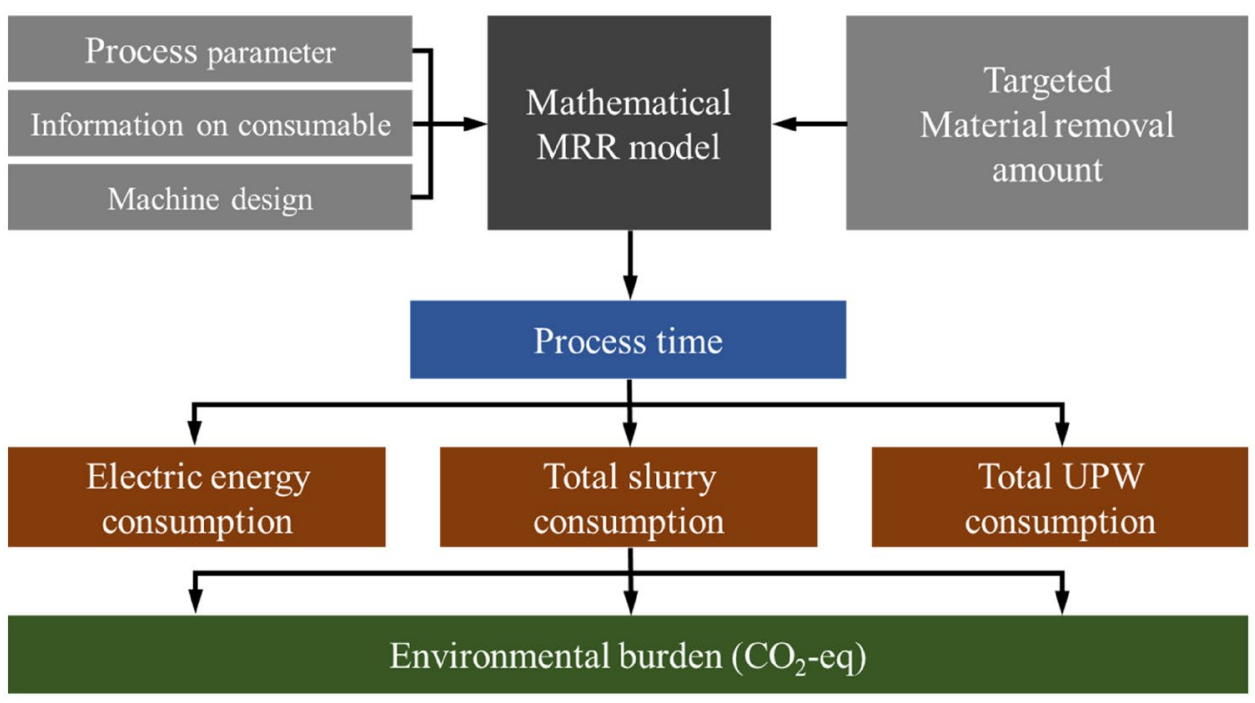

$C D E_{s}$ refers to the CDEs during wetting and polishing. $C D E_{U}$ denotes CDEs during idling, pad conditioning, and rinsing. $C D E_{\text {etc }}$ represents CDEs of long lifespan consumables, and Lee's research assumed that its effect is negligible. In the study, the carbon intensities of UPW, $\mathrm{H}_{2} \mathrm{O}_{2}$, citric acid, BTA, and abrasive particle were $0.0104 \mathrm{gCO}_{2}$-eq/g, $1.0 \mathrm{gCO}_{2}$-eq/g, $0.26 \mathrm{gCO}_{2}$-eq/g, $1.4 \mathrm{gCO}_{2}$-eq/g, and 0.26 $\mathrm{gCO}_{2}$-eq/g, respectively. According to Lee's study, the BTA used as the corrosion inhibitor exhibited the greatest environmental burden, followed by $\mathrm{H}_{2} \mathrm{O}_{2}$ and abrasive particles, while citric acid caused the lowest environmental burden. These results show that oxidizer, complexing agent, and abrasive reduce processing time by increasing material removal rates, but BTA prevents excessive etching of the lower area of the pattern in the pattern CMP, thereby increasing planarization efficiency. Therefore, it is desirable to balance environmental burdens and productivity by properly adjusting the concentration within the slurry. Zhang et al. [32] introduced $\mathrm{H}_{2} \mathrm{O}_{2}$, malic, and citric acid-based slurry for environment-friendly CMP for mercury cadmium telluride (MCT) semiconductors. Therefore, extractable acids from fruits may help reduce the environmental burden caused by using slurry in CMP.

\section{CMP Wastewater Treatment}

CMP wastewater is produced during CMP and post-CMP cleaning processes. Therefore, CMP wastewater includes abrasive particles and chemicals used in CMP slurry and post-CMP cleaning. For example, abrasive particles, such as silica $\left(\mathrm{SiO}_{2}\right)$, alumina $\left(\mathrm{Al}_{2} \mathrm{O}_{3}\right)$, magnesia $\left(\mathrm{MnO}_{2}\right)$, ceria $\left(\mathrm{CeO}_{2}\right)$, and zirconia $\left(\mathrm{ZrO}_{2}\right)$, including oxidizers for metal CMPs, such as $\mathrm{H}_{2} \mathrm{O}_{2}, \mathrm{CuSO}_{2}$, and $\mathrm{KMnO}_{4}$, may be included in CMP wastewater [33, 34]. Chemical agents, such as surfactants, buffing agents, complexing (or chelating) agents, and corrosion inhibitors, are also included in wastewater [33, 34]. According to Lo's study [21] and previous studies on CMP [2, 33-42], CMP and post-CMP cleaning wastewater contains various chemicals and materials, as listed in Table 1.

Nanomaterials (NMs) of $\mathrm{SiO}_{2}, \mathrm{CeO}_{2}$, and $\mathrm{Al}_{2} \mathrm{O}_{3}$ are used in liquid slurries for numerous industrial applications, such as CMP processes, and used multiple times during the production of computer chips. These NMs are dispersed into CMP slurry, used once and released into the sewer. The global production of these three NM CMP slurry materials exceeds 5000 ton per year, making them one of the highest in global nanomaterial production. [43]. Among them, $\mathrm{CeO}_{2}$ nanoparticles market is projected to reach USD 630.2
Table 1 Chemicals and materials in CMP and postCMP cleaning wastewater [24]

\begin{tabular}{lll}
\hline Classification & Chemicals or materials & References \\
\hline Abrasives & $\mathrm{SiO}_{2}, \mathrm{Al}_{2} \mathrm{O}_{3}, \mathrm{CeO}_{2}, \mathrm{MnO}_{2}, \mathrm{ZrO}_{2}, \mathrm{TiO}_{2}$ & {$[21,33-35]$} \\
pH buffer solutions & $\mathrm{KOH}, \mathrm{NH}_{4} \mathrm{OH}, \mathrm{HNO}_{3}$ or organic acids & {$[21]$} \\
Oxidants & $\mathrm{H}_{2} \mathrm{O}_{2}, \mathrm{Fe}\left(\mathrm{NO}_{3}\right)_{3}, \mathrm{KIO}_{3}, \mathrm{Fe}(\mathrm{KCN})_{3}, \mathrm{KMnO}_{4}, \mathrm{CuSO}_{2}$ & {$[21,33-35]$} \\
Etching materials & $\mathrm{SiO}_{2}, \mathrm{~W}, \mathrm{Al}, \mathrm{Cu}, \mathrm{Na}, \mathrm{K}, \mathrm{Ni}, \mathrm{Fe}, \mathrm{Zn}$ & {$[21]$} \\
Other agents & $\mathrm{Surfactants}$ chelating agents, corrosion inhibitors & {$[2,21,36-42]$} \\
\hline
\end{tabular}


Million by 2022 from USD 259.7 Million in 2017, at a compound annual growth rate (CAGR) of 19.4\% from 2017 to 2022 [44]. Therefore, CMP wastewater can be seen as a major source of NM in sewer systems, and eventually in the environment. From the CMP application, approximately $5 \%$ of the $\mathrm{CeO}_{2}$ mass may reach in the natural environment.

The on-site industrial treatments include precipitation of metals or sorption of pollutants onto the precipitated materials. Precipitated materials are gravitationally settled and disposed of in landfills, as shown in Fig. 7. The materials that are not removed are discharged into municipal sewer systems, and they enter municipal wastewater treatment plants that often use biological treatments designed to remove the nutrients (carbon, nitrogen, and phosphorous), but are also capable of removing the nanomaterials [43].

To satisfy the national and domestic regulations of the semiconductor industry, CMP wastewater must be properly treated for environmental safety. For example, Taiwan recycles $80 \%$ of the water used in IC factories [45]. The CMP wastewater treatment process is divided into two main categories [21].

(a) Combination of chemical coagulation and advanced treatment: gravity sedimentation, membrane filtration and dissolved air flotation after chemical coagulation (pretreatment).

(b) Direct use of filtration and electrocoagulation: ultrafiltration, electrocoagulation /electrodecantation, or microfiltration using an external electric field.

Gravity sedimentation uses the gravitational force to separate solid and liquid in the CMP wastewater. Lo and Lo [21] introduced a ceramic filtration method combined with chemical coagulation pretreatment. Liu et al. [46] studied a dissolved air flotation (DAF) of CMP wastewater, and their proposed treatment system was able to finish the floatation reaction in less than $5 \mathrm{~min}$. Tsai et al. [47] proposed a coagulation process for CMP wastewater using nanobubbles, with a 10-20\% recycle ratio of CMP wastewater within $1 \mathrm{~h}$ of hydraulic retention time. Lien and Liu [48] treated CMP wastewater by using a dispersed air flotation (DiAF). They demonstrated that they could effectively remove particles from the wastewater by using a collector of cationic surfactant, cetyltrimenthyl ammonium bromide (CTAB) in DiAF process. However, it is necessary to remove additional surfactants within the wastewater and the high turbidity is a disadvantage. Lin and Yang [49] utilized chemical coagulation and reverse osmosis (RO) with a microfilter for removing oxide particles and inorganic/organic pollutants.

One of the efficient ways to remove particles from CMP wastewater is by filtration using membrane. Browne et al. [50] showed that the oxide particles suspended in the CMP wastewater could be remove with an ultrafiltration (UF) method. Juang et al. [51] used UF and RO separation method at the same time, and they were able to eliminate $99 \%$ of fine particles through UF pretreatment. Sanusi et al. [52] recycled spent tungsten CMP slurry using various ultrafiltration membranes such as polysulfone (PS), polyethersulfone (PES), and polyvinylidene fluoride (PVDE).

Electrocoagulation (EC) is one of the most efficient and inexpensive technologies that can increase turbidity of wastewater by removing particles from wastewater [53-56]. Belongia et al. [57] showed that alumina and silica particles of $200 \mathrm{~nm}$ in diameter could be precipitated from suspension. Den and Huang [58] proved that nano-sized silica particles can be removed from CMP wastewater using continuous-flow EC processes with vertical-channels. Lai and Lin [59] said the use of $\mathrm{Al}$ and $\mathrm{Fe}$ as anode and cathode in the EC process of CMP wastewater would be advantageous for $\mathrm{Cu}$ removal and turbidity reduction. They then used the electrocoagulation system to study the sludge setting characteristics in Cu CMP wastewater [60]. Drouiche et al. [61] showed that oxide particles, fluoride and sulfate ions contained in CMP wastewater from photovoltaic wafer manufacturer can be removed through EC.

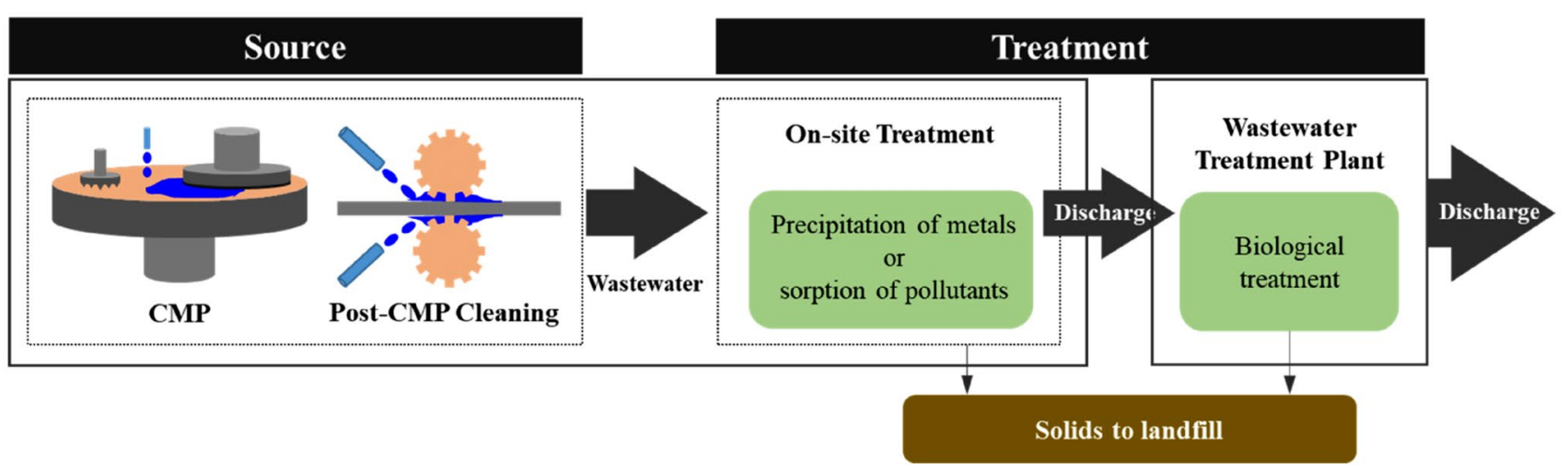

Fig. 7 Source and treatment of CMP nanomaterials used in the semiconductor industry (Redrawn and modified figures of reference 46) [43] 
Electrodecantation (ED) is a separation and purification method of colloidal dispersions based on electrophoretic migration of colloids. Stamberger [62] used a ED method to purify and concentrate colloidal dispersions. He showed that $\mathrm{ED}$ is one of the ways to efficiently remove small particles from wastewater. Belongia et al. [57]. used electrodecantation and electrocoagulation simultaneously to remove alumina and silica particles.

Some researchers have proposed an electro-microfiltration method to increase the efficiency of microfiltration for CMP wastewater. Weigert et al. [63] studied a crossflow electrofiltration using a polyamide membrane and were able to significantly increase specific permeate rate compared to microfiltration without electric filed. Sung et al. [64] used a Gortex ${ }^{\mathrm{TM}}$ (Maryland, USA) membrane for the electrofiltration of alumina and silica colloids. Yang et al. [65-67] conducted a series of studies that applied crossflow electrofiltration to the treatment of CMP wastewater. They proposed an electrically enhanced crossflow microfiltration (EECMF) method [65], electrofiltration/electrodialysis process [65], and tubular $\mathrm{TiO}_{2} / \mathrm{Al}_{2} \mathrm{O}_{3}$ composite membranes [67] for treating CMP wastewater.

CMP wastewater treatment systems include collection, $\mathrm{pH}$ adjustment, oxidizer removal, organics removal, suspended solid treatment, and trace metal removal [68]. The water separated from the CMP wastewater is recycled for reuse. However, research on the reuse of abrasive particles separated from CMP wastewater is not well known. Lee et al. [69] recycled CMP abrasive particles as a resource in concrete. They compared cylindrical specimens of CMP sludge-blended cement concrete (SBCC) with ordinary Portland cement concrete (OPCC) specimens. Their research shows the possibility of replacing some of the cement with CMP sludge, and provides a good example of recycling abrasive particles in CMP wastewater.

\section{Challenges for CMP Slurry and Slurry Injection System}

Owing to the nature of CMP applied to semiconductor processes that require high reliability, the reuse or recycling of slurries has not been successful until now. Considering the trend that the gate size shrinks from several tens of nanometers to several nanometers in future, the lack of guarantee of the integrity of CMP results can make it difficult to reuse the slurry. The number of CMP process steps and the amount of slurry used are expected to increase in future. To reduce the total amount of slurry used, it is necessary to optimize the amount of slurry used in the individual CMP process steps.

As the slurry consists of a mixture of abrasives and the solution, considering the amount of $\mathrm{CO}_{2}$ generated during the production and disposal of particles, it is beneficial for the environment to use a slurry with a low abrasive concentration or an abrasive-free slurry even with the same amount of slurry used [70]. Additionally, considering that the amount of slurry used is proportional to the product of flow rate and polishing time, the total amount used can be reduced by completing the given CMP process within the minimum time at the optimum flow rate. The methods proposed in studies for reducing the environmental burden caused by the use of slurry in the CMP field are classified as follows.

(a) Increasing MRR by strengthening the chemical reaction [71] and mechanical material removal

(b) Reducing abrasive concentration or using an abrasivefree slurry

(c) Minimizing additional polishing time by improving the uniformity of polishing

(d) Increasing slurry participation in material removal using a slurry injection system

However, there is a limit to reducing the environmental burden caused by CMP by increasing the MRR through changes in slurry components. Changes in the slurry components should be determined by considering the environmental burden caused by the use of the slurry itself and the reduction in processing time owing to the increase in MRR. Mixed-abrasive CMP methods have been introduced to increase mechanical material removal by simultaneously using different types of abrasives, such as $\mathrm{SiO}_{2}, \mathrm{Al}_{2} \mathrm{O}_{3}$, $\mathrm{CeO}_{2}, \mathrm{ZrO}_{2}, \mathrm{TiO}_{2}$, and $\mathrm{MnO}_{2}$. Jindal et al. [72] has shown that without adding any chemical additives, mixed abrasive slurry (MAS) composed of $\mathrm{Al}_{2} \mathrm{O}_{3}$ and $\mathrm{SiO}_{2}$ particles can achieve higher MRR and more desirable $\mathrm{Cu} / \mathrm{Ta} / \mathrm{SiO}_{2}$ selectivity. Seo and Lee [73] found that $\mathrm{SiO}_{2}-\mathrm{TiO}_{2}$ MAS is more efficient in terms of reducing the surface roughness of $\mathrm{Ba}_{0.6} \mathrm{Sr}_{0.4} \mathrm{TiO}_{3}$ (BST) compared to $\mathrm{SiO}_{2}, \mathrm{Al}_{2} \mathrm{O}_{3}$, and $\mathrm{TiO}_{2}$ single abrasive slurry for BST. Park et al. [74] diluted $\mathrm{KOH}-$ based fumed silica slurry in $\mathrm{SiO}_{2} \mathrm{CMP}$ at a ratio of 1:10 with DIW and added $\mathrm{ZrO}_{2}$ particles to the slurry to investigate the effect of $\mathrm{ZrO}_{2}$ concentration and dispersion time on the CMP results. Lee and Jeong [75] proposed an MAS for mixing two $\mathrm{KOH}$-based colloidal slurries with different particle sizes. They used colloidal silica particles with $30 \mathrm{~nm}$ and $70 \mathrm{~nm}$ diameters with $30 \mathrm{wt} \%$ abrasive concentration, indicating the highest MRR when diluted at 2:1 ratio. In addition, MAS using two $\mathrm{SiO}_{2}$ heterogeneous particles of different shapes has been reported [76, 77]. MAS consisting of $\mathrm{CeO}_{2}$ and $\mathrm{SiO}_{2}$ has also been studied for $\mathrm{SiO}_{2} \mathrm{CMP}$ and has been reported to be capable of obtaining a higher MRR than a single abrasive slurry (SAS) [78, 79]. Lee et al. [80] proposed MAS for SiC CMP using nanodiamond and colloidal silica particles and improved the MRR using diamond and surface roughness using soft silica particles. Table 2 
Table 2 CMP studies on MAS and target materials

\begin{tabular}{lll}
\hline MAS & Target material & References \\
\hline $\mathrm{Al}_{2} \mathrm{O}_{3}+\mathrm{SiO}_{2}$ & $\mathrm{Cu}, \mathrm{Ta}, \mathrm{SiO}_{2}$ & {$[71]$} \\
$\mathrm{SiO}_{2}+\mathrm{TiO}_{2}$ & $\mathrm{Ba}_{0.6} \mathrm{Sr}_{0.4} \mathrm{TiO}_{3}$ & {$[73]$} \\
$\mathrm{SiO}_{2}+\mathrm{ZrO}_{2}$ & $\mathrm{SiO}_{2}$ & {$[74]$} \\
$\mathrm{SiO}_{2}(\mathrm{Large})+\mathrm{SiO}_{2}$ (Small) & $\mathrm{SiO}_{2}$ & {$[75]$} \\
$\mathrm{SiO}_{2}+\mathrm{SiO}_{2}$ (Various shapes) & $\mathrm{SiO}_{2}$ & {$[76,77]$} \\
$\mathrm{SiO}_{2}+\mathrm{CeO}_{2}$ or SiO2 coated with $\mathrm{CeO}_{2}$ & $\mathrm{SiO}_{2}$ & {$[77-79]$} \\
$\mathrm{Diamond}_{2} \mathrm{SiO}_{2}$ & $\mathrm{SiC}$ & {$[80]$} \\
\hline
\end{tabular}

presents the details of previous CMP studies on MAS and target materials. Figure 8 shows the mechanism on MAS CMP. The previously introduced mechanisms of MAS CMP are as follows.

(a) Large particles are coated with small particles by the charge difference between the particles (Fig. 7a) [72].

(b) Large and small particles participate in material removal independently; large particles serve the function of material removal, and small particles cause improvement in the surface roughness (Fig. 7b) [75].

In CMP, the abrasive particles play a role in increasing the MRR; however, they sometimes cause defects, such as scratches. Abrasive particles from natural resources are becoming increasingly depleted. Therefore, from an environmental perspective, there is a growing interest in abrasivefree CMP (AF-CMP). It is known that AF-CMP can improve CMP productivity by reducing scratches as the abrasive particles after CMP do not remain on the surface of the wafer; the post-CMP cleaning process is convenient and can reduce dishing and erosion defects [81-83]. Research on AF-CMP has focused on metal CMP, which largely relies on chemical reactions instead of mechanical material removal. Ramakrishnan et al. [84] compared dicarboxylic acids, such as oxalic acid, malonic acid, succinic acid, and glutaric acid, used as complexing agents in AF-CMP solution for $\mathrm{Cu}$. They found that oxalic acid and malonic acid solutions showed high MRR in AF-CMP for copper. Yang et al. [85] reported that glycine acts as a corrosion inhibitor in alkaline $\mathrm{H}_{2} \mathrm{O}_{2}$ based AF-CMP solution for molybdenum (Mo), which is used as an electrode in solar cells and switches for liquid crystal displays (LCDs). Hara et al. [86] proposed a new abrasive-free planarization method called catalyst-preferred etching (CARE) for SiC substrates. They used a Pt solid pad as a catalyst in a hydrofluoric acid solution instead of a polyurethane pad, which is commonly used for CMP pads. Pandija et al. [87] studied oxalic acid as a complexing agent for an $\mathrm{H}_{2} \mathrm{O}_{2}$-based abrasive-free $\mathrm{Cu}$ CMP solution. They obtained the maximum MRR at $\mathrm{pH} 3$ with $0.065 \mathrm{M}$ oxalic acid and $5 \mathrm{wt} \% \mathrm{H}_{2} \mathrm{O}_{2}$.

The amount of slurry used in individual processes has a direct correlation with WIWNU. Assuming an ideal CMP process in which the WIWNU is $0 \%$, the CMP process time has a minimum value. However, as the WIWNU deteriorates, the polishing time increases to polish the remaining thin film even after the film materials in a partial area of the wafer are completely removed [88]; thus, the amount of slurry per wafer increases. Therefore, when the WIWNU is high, the deviation in the flatness of the device in the wafer increases, but the amount of slurry used increases proportionally [89]. The most dominant factor that influences the WIWNU is the uniformity of pressurization of the membrane [90-92]. Therefore, improving the uniformity of polishing by developing a high-performance multi-zone membrane structure is a key research direction for reducing the amount of slurry and improving the device yield.

In addition, WIWNU is directly affected by the flatness of the pad [6] along with the slurry supply method [93-95]; the effect of the flatness of the pad on WIWNU will be discussed in the next section. In one of the studies on slurry supply method, the slurry is supplied in the form of a spray over the pad surface, which results in a high polishing rate and low WIWNU with a small amount (a)

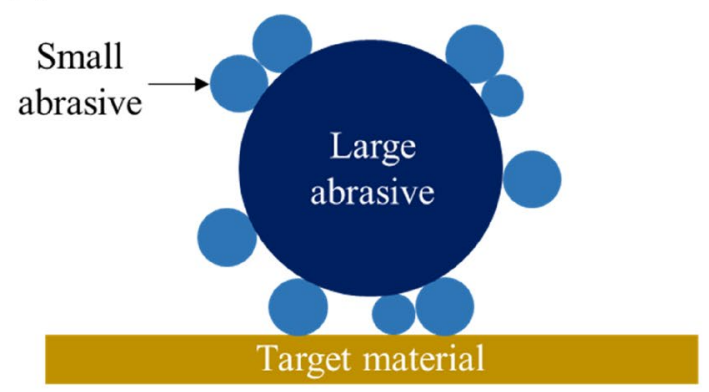

(b)

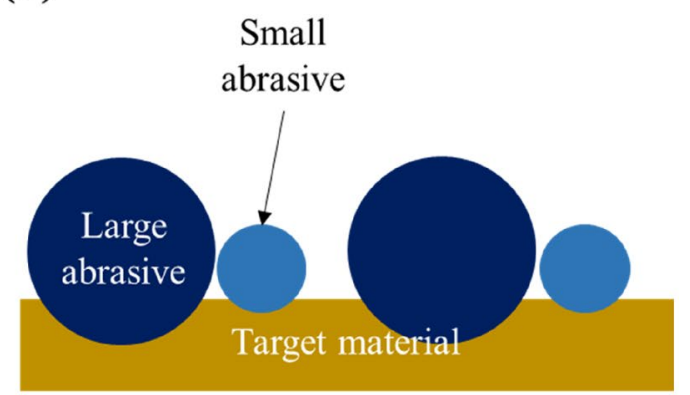

Fig. 8 Mechanisms on MAS CMP proposed by a Jindal et al. [72] and b Lee and Jeong [75] (Redrawn and modified figures of reference 72 and 75) 

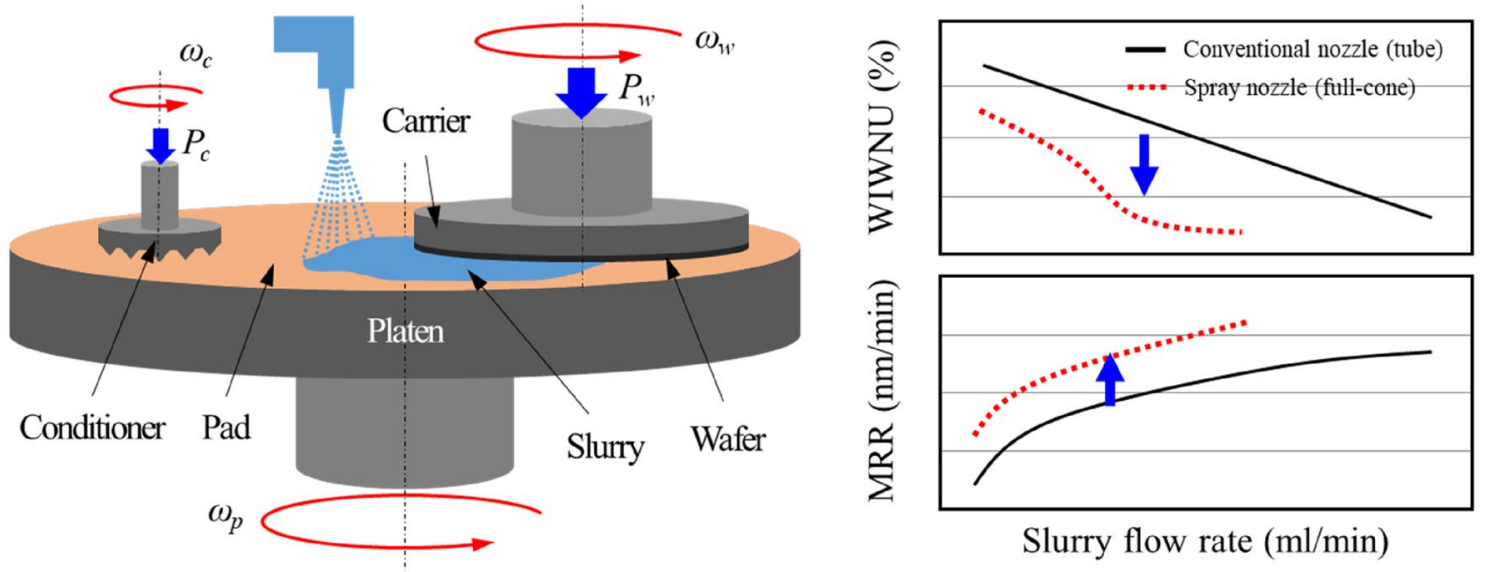

Fig. 9 Schematic of CMP using spray slurry nozzle proposed by Lee et al. [93] and comparison of WIWNU and MRR for conventional slurry nozzle and spray slurry nozzle (Redrawn and modified figures of reference 93)

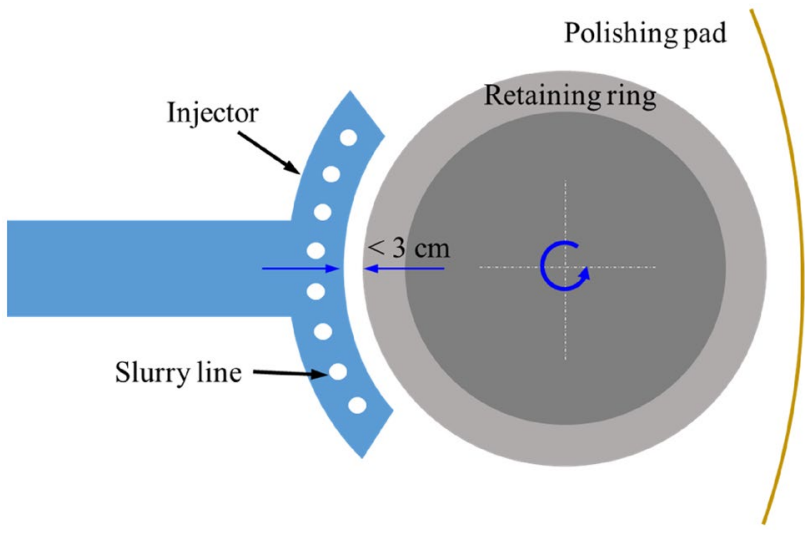

Fig. 10 Schematic of slurry injection system proposed by Liao et al. (Redrawn and modified figures of reference 94) [94]

of slurry (Fig. 9) [93]. The authors have compared a conventional tube slurry and spray slurry nozzle at different slurry flow rates and spray nozzle heights. The experimental results based on slurry flow rate showed that the spray nozzle had a higher MRR and lower WIWNU than the conventional nozzle, resulting in a $21 \%$ and $52 \%$ slurry flow rate reduction. Therefore, this method can reduce the amount of slurry used. Liao et al. [94] proposed a crescent-shaped slurry injection system for CMP (Fig. 10). The proposed slurry injection system was placed adjacent to the retaining ring, allowing fresh slurry to be supplied more efficiently to the leading edge of the retaining ring. Araca Incorporated introduced Araca slurry injection system (SIS) with multiple injection points for uniform bow wave thickness of slurry around retaining rings [95].

\section{Challenges for CMP Pad}

As of 2020, approximately 2.5-3 million CMP polishing pads are expected to be used annually worldwide, with an annual growth rate of 5.8\% [96]. Assuming that the thickness of one pad is $2 \mathrm{~mm}$, if the polishing pads used every year are stacked in a row, the height becomes $4 \mathrm{~km}$. The total amount of discarded pads can be reduced by increasing the life of the pads.

When the uniformity of the pad cut rate (PCR) is uniform $(0 \%)$, the lifetime of the pad is determined by the following equation.

$T_{\text {life }}=\frac{C \times G}{P C R}$

where $T_{\text {life }}$ is the lifetime of the pad; $G, C$, and $P C R$ are the groove depth, proportion constant of the groove usage limit $(0 \leq C \leq 1)$, and pad cut rate, respectively. As a rule of thumb, Eq. (2) shows that the lifetime of the pad can be increased with a low $P C R$, deep groove, and extended groove usage. However, a certain radial position of the pad is removed faster than other areas; hence, the factor that contributes the most to the pad life is premature profile deterioration due to improper conditioning processes and excessive pad cut rate more than necessary. Lee et al. [6] defined the pad profile with the following parameters: the maximum depth of pad wear $\left(h_{\max }\right)$, average depth of pad wear $\left(h_{\mathrm{avg}}\right)$, and horizontal distance from the wafer center to the position $P$ where the maximum pad wear occurs $(e)$, as shown in Fig. 11. Their experiments showed that as the polishing pad wears unevenly by CMP conditioning, MRR decreases sharply after a certain point as $h_{\text {avg }}$ and $h_{\max }$ increase, and WIWNU increases (Fig. 12). 


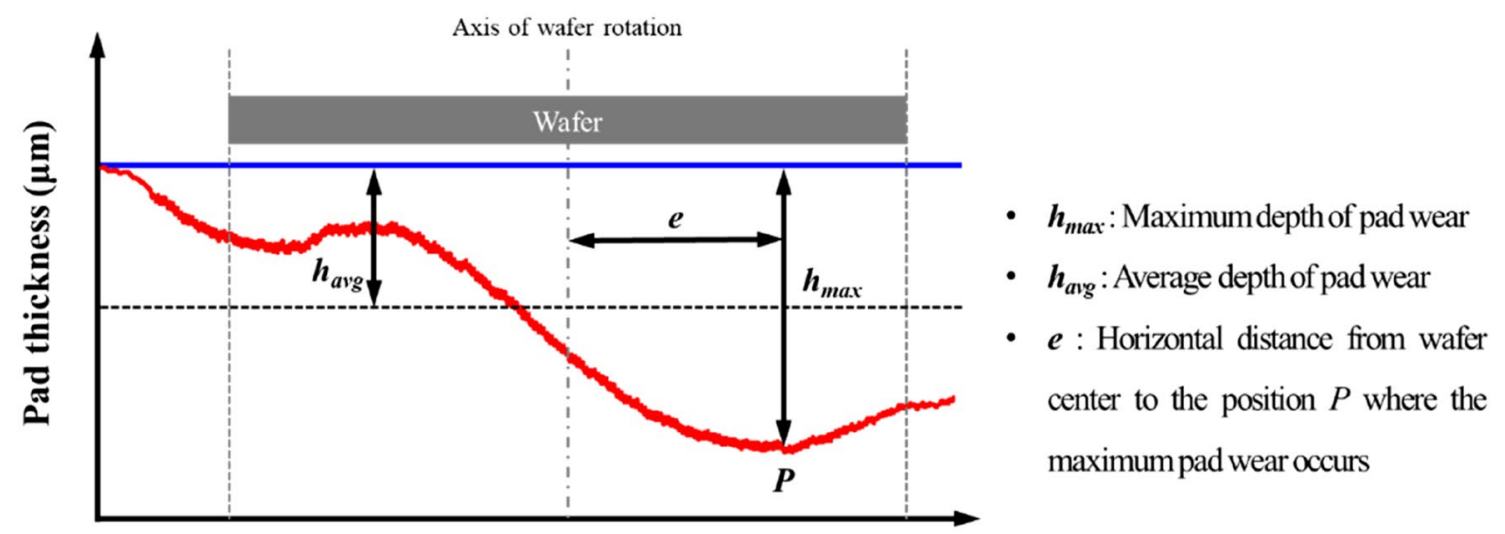

Distance from pad's center $(\mathrm{mm})$

Fig. 11 Definition of pad profile proposed by Lee et al. (Redrawn and modified figures of reference 6) [6]

(a)

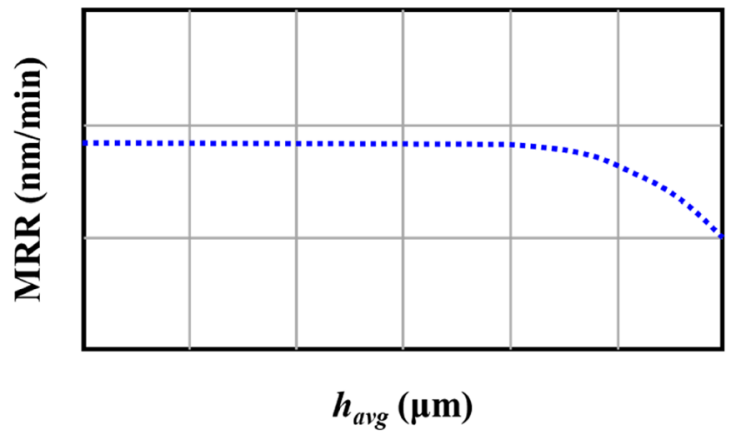

(b)

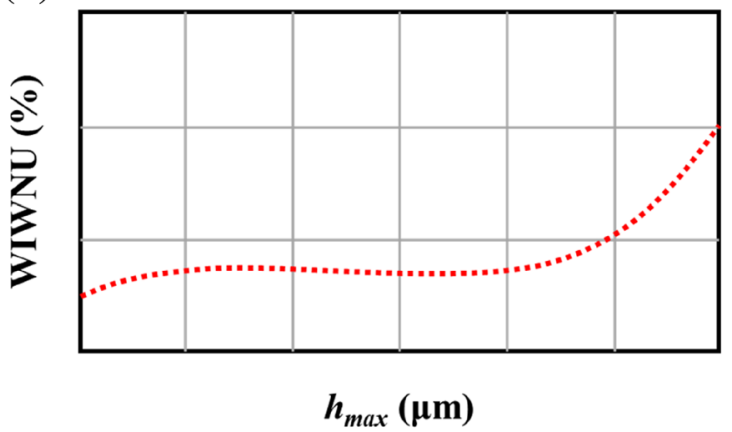

Fig. 12 MRR and WIWNU trends with respect to $\mathbf{a} h_{\text {avg }}$ and $\mathbf{b} h_{\max }$ reported by Lee et al. (Redrawn and modified figures of reference 6) [6]

Pad profiles can deteriorate earlier owing to improper conditioning processes. In this case, some grooves in the pad radius are overworn more quickly than in other areas; thus, the pad should be discarded, despite other areas of the pad being functional [97]. In addition, even when the conditioning recipe is optimized, the pad profile can easily deteriorate if the conditioner's gimbal resistance is not uniform with respect to the gimbal axis owing to the deterioration of the conditioner parts or components. In this case, the life of the pad is drastically reduced. Further, the life of the pad is greatly influenced by the width of the groove under the same conditioning process [98]. This is because the groove width directly affects the actual contact pressure delivered by the conditioner.

The improvement in pad life increases its usage time and substantially contributes to reducing the cost of consumables $(\mathrm{CoC})$ of the entire CMP process. Heuy et al. [98] reported that the pad cost contributes to approximately one-third of the total CMP CoC. In their case study, the average CMP pad life was found to be 250 wafers/pad with a variance of 100-400 wafers/pad. The pad CoC increases significantly for pad lives of $<350$ wafers/pad. The pad CoC at 350 wafers/ pad is half that at 225 wafers/pad [98].

The current pad life has been increased to approximately $20-40 \mathrm{~h}$ depending on the users and processes; in terms of the number of wafers processed per pad, more than 2000 wafers can be polished with a single pad [99]. The reasons for this improvement can be summarized as the development of a high-precision conditioning system to realize low-pressure conditioning technology, a diamond conditioner that can maintain the cutting ability even at low pressures, and real-time pad profile control technology $[100,101]$.

Stable low-pressure conditioning technology is realized by the advancement of precise pressure control technology by reducing the friction in the mechanical pressurizing system and improving the precision of the pneumatic pressure control system. The advancement of a diamond conditioner that controls the amount and position of active abrasives to maintain the cutting ability even at low pressures plays an important role in extending the pad life [102]. In addition, constant cutting performance can be maintained for a long time using a chemical vapor deposition (CVD) diamond 
conditioner with a naturally uniform protrusion height of cutting tips, which realizes a low cutting depth throughout the conditioner surface [103]. Finally, the core of the conditioning profile control technology constitutes the development of a real-time pad profile measurement technology and a method to control the weighting function of the conditioning strength according to the pad radius using the result of profile measurement [104]. Using this technology can extend the pad lifespan and maintain pad thickness reduction below the required limit during the pad lifespan [100, 101].

The pad life depends on the conditioner's cutting speed (pad cutting rate; PCR). Closed-cell-type pads can maintain their polishing ability only when the surface roughness of the pad is formed by the conditioner. While pad conditioning has the advantage of maintaining the polishing performance, it has the disadvantage that the CMP characteristic cannot be maintained without conditioning stability of the pad. These shortcomings naturally lead to the study of micro-replicated patterned pads that do not require a conditioning process. The research conducted by Tseng et al. [99] using micro-replicated $3 \mathrm{M}$ pads (MR pads) can provide important data for new pad studies where conditioning is not performed. In the case of the MR pad, the surface roughness was formed on the surface of the pad in advance, and it could be used in CMP without conditioning. According to the results, the MR pad achieved CMP process results with more consistent wafer-to-wafer stability and repeatability in removal rate, WIWNU, and defectivity up to 2000 wafer passes compared to a conventional pad with a diamond tip conditioner. A significant reduction in within-die non-uniformity (WIDNU) was confirmed by testing gate electrical conductance and transmission electron microscopy (TEM) measurement of the physical gate height. In addition, reduction in at-level metal loss defects after replacement metal gate (RMG) CMP and reduction in prior-level topography-driven defects, such as puddles and missing patterns, were observed after trench silicide (TS) CMP [99]. Research on these new pads can be applied to reduce conditioner waste and prevent microplastic contamination in wastewater.

Recently, Son et al. [105] introduced a contact-areachangeable CMP conditioning method (Fig. 13) and controlled the pad wear profile by adjusting the contact area between the pad and conditioner during pad conditioning. They used contact-area-changeable conditioning to allow partially flat pad wear in the area where the polishing pad and wafer are in contact, thus increasing the pad's lifetime, compared to the conventional swing-arm conditioning method. Figure 14 shows the MRR distributions of conventional conditioning and contact-area-changeable conditioning.

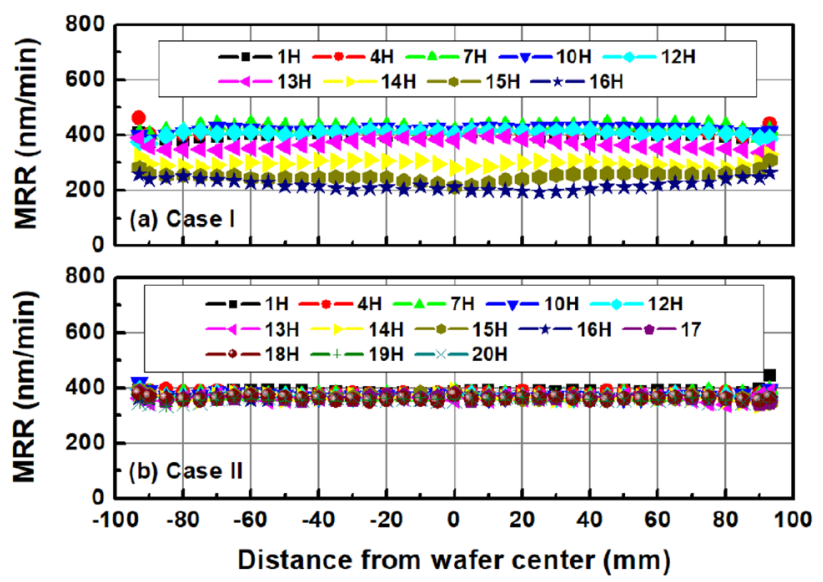

Fig. 14 MRR distribution as a function of conditioning time: a conventional conditioning and $\mathbf{b}$ contact-area-changeable conditioning conditioner ( Adapted from reference 105 (Open Access)) [105]

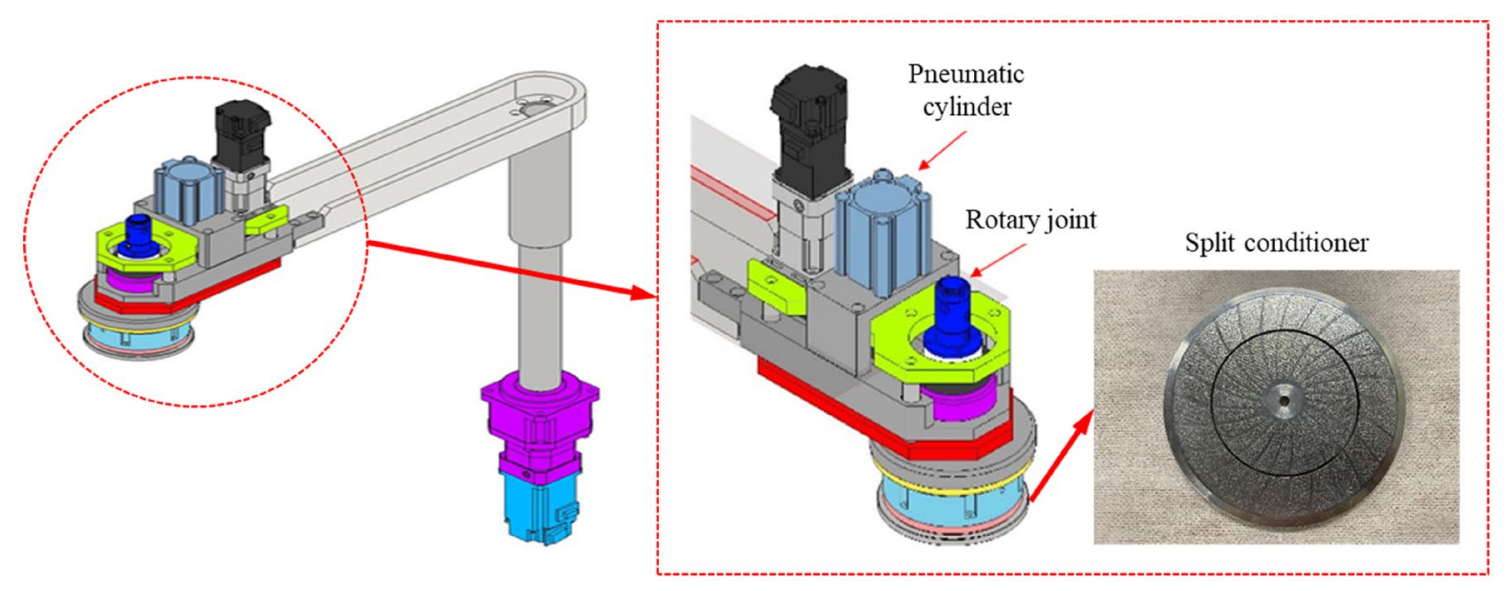

Fig. 13 Contact-area-changeable conditioning system and split conditioner ( Adapted from reference 105 (Open Access)) [105] 


\section{Hybridization of CMP System}

To increase the processing efficiency in CMP, high-speed and high-pressure conditions can be used. However, these conditions in the CMP can improve productivity by increasing the MRR, but are vulnerable to defects, such as scratches and delamination of thin films. Researchers are attempting to increase the MRR by simultaneously using other physical and chemical elements, in addition to chemical reactions in the CMP process.

Kurokawa et al. [106] proposed a CMP method using a bell-jar-type CMP machine and $\mathrm{KMnO}_{4}$ as an oxidizer. Belljar CMP is a method that increases the processing efficiency of the CMP by conducting it in a chamber to control the ambient pressure, thereby enabling the application of CMP in various gas environments. This method is reported to be able to improve the MRR by facilitating the oxidation of $\mathrm{SiC}$ substrates in nitrogen $(\mathrm{N})$ and oxygen $\left(\mathrm{O}_{2}\right)$ atmospheres. To improve the MRR of hard-to-process crystals, Doi et al. [107] proposed a process method that combines plasmachemical vaporization machining (P-CVM) and CMP with a bell-jar-type CMP machine.

Lee et al. [108] used an electrolytically ionized slurry for performing CMP of $\mathrm{Cu}$. They used a DC power supply to ionize the slurry (ion-rich slurry) through the electrodes to increase the amount of $\mathrm{OH}$ radicals $(-\mathrm{OH})$ in the slurry, thereby increasing the chemical reactivity of the slurry and $\mathrm{Cu}$ (Fig. 15). They proved that the MRR and its uniformity can be controlled by the applied voltage.

Jo et al. [109] proposed a hybrid CMP slurry supply system using ionization and atomization (Fig. 16). They ionized the CMP slurry in a slurry tank with an AC power supply and electrode. The slurry was sprayed over the polishing pad via a twin-fluid atomizer that used oxygen

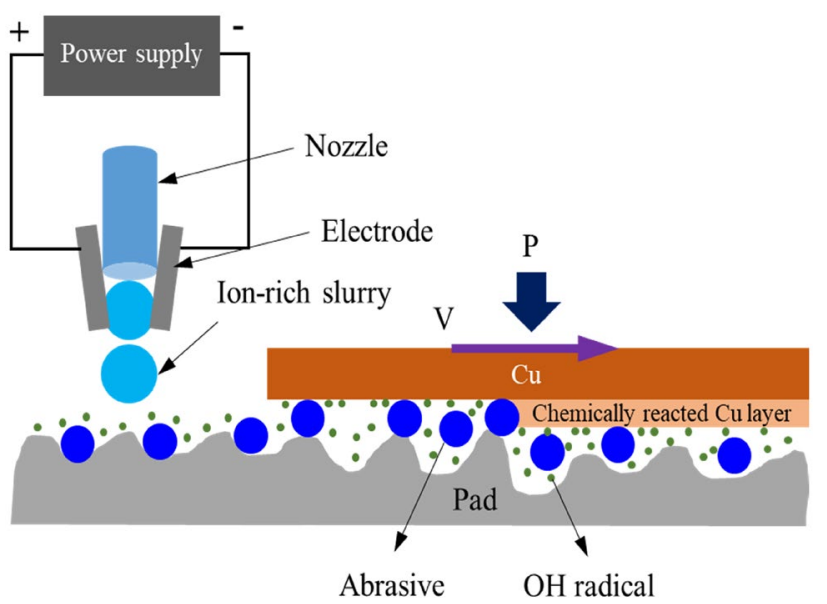

Fig. 15 Electrolytic CMP system and material removal mechanism

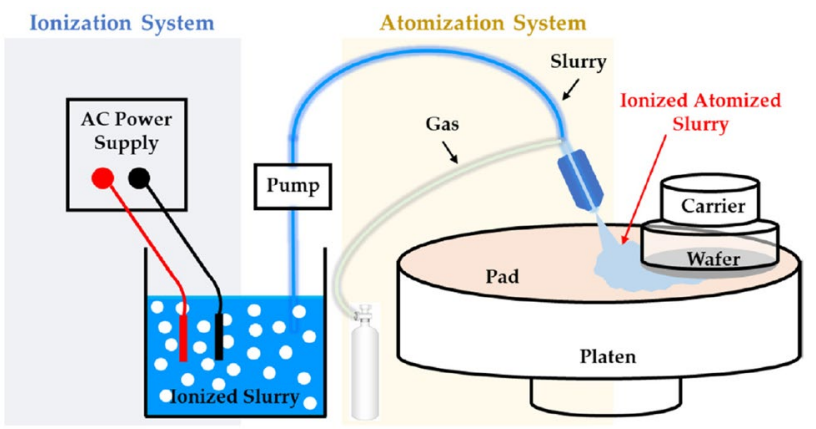

Fig. 16 Hybrid slurry supply system proposed by Jo et al. conditioner ( Adapted from reference 109 (Open Access)) [109]

or nitrogen gas. Figure 17 demonstrates the slurry flow around the carrier and pad boundaries. The proposed slurry supply system distributes the slurry uniformly over the polishing pad, unlike in a conventional slurry supply system. In Cu CMP, the hybrid slurry supply system could increase the MRR by $23 \%$ and WIWNU decreased by $25 \%$, compared with those in the conventional CMP system.

Another method of activating $\mathrm{OH}$ radicals is photoelectrochemical (PEC) planarization using ultraviolet (UV) light and a catalyst. Li et al. [110] conducted a study to improve the MRR of GaN using hydroxyl radicals with UV light and iron. Murata et al. [111] used five polishing platens (non-metal, $\mathrm{W}, \mathrm{Ta}, \mathrm{Ni}$, and $\mathrm{Fe}$ ) that act as catalysts for chemical planarization of GaN. Among the five platens, the highest MRR was observed when the Fe platen was used as the catalyst. Wang et al. [112] also studied the photocatalytic reaction mechanism of GaN CMP with $\mathrm{H}_{2} \mathrm{O}_{2}$ based slurry and UV light. They found that using a UVA lamp (wavelength: 400-315 nm) in GaN CMP resulted in a higher MRR than using UVC (wavelength: 280-190 nm) and incandescent lamps. UVA irradiation accelerates the decomposition of $\mathrm{H}_{2} \mathrm{O}_{2}$ and production of hydroxyl radicals, thereby enhancing the oxidation reaction of GaN. Figure 18 shows a comparison of the material removal mechanisms of conventional GaN CMP and PEC planarization. Yuan et al. [113] investigated the CMP of $4 \mathrm{H}-\mathrm{SiC}$ using $\mathrm{UV}-\mathrm{TiO}_{2}$ photocatalysis. Table 3 presents the aforementioned hybrid CMP systems.

Various methods are being attempted to improve low MRR in CMP, but while there are positive effects of reducing time in the production process, it is unlikely that most alternative technologies have significantly reduced the environmental burden due to the additional use of new energy sources or devices. Therefore, it seems necessary to closely analyze the environmental impacts of the developed alternative processes. 


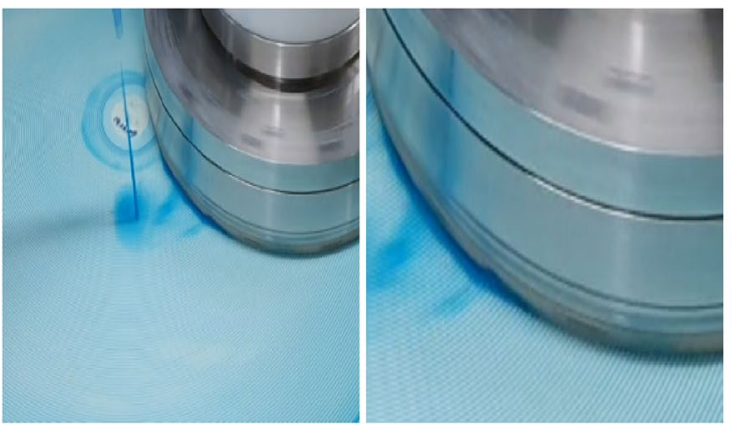

(a)

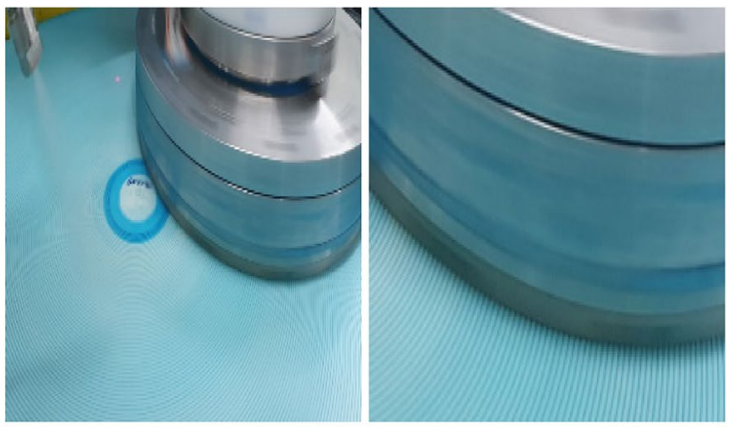

$(\mathbf{b})$

Fig. 17 Images of slurry flow around the carrier and polishing pad boundaries: a conventional slurry supply system and b hybrid slurry supply system ( Adapted from reference 109 (Open Access)) [109]

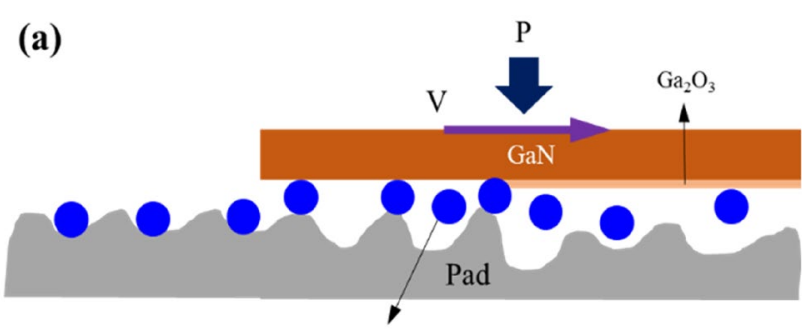

Abrasive

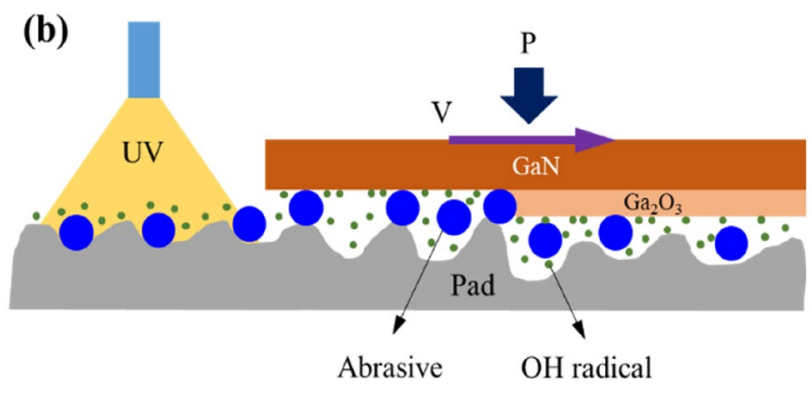

Fig. 18 Material removal mechanism of GaN: a conventional CMP and $\mathbf{b}$ photoelectrochemical planarization

\section{Future of CMP}

The coronavirus pandemic has exerted enormous pressure on world society and forced a host of changes in our lifestyle. When it recedes in the future, experts expect that the older and more familiar approaches to working would return. Harvard experts say that some of our adaptations have accelerated the existing trends, such as the development of a cashless society, increase in remote working, and decline in offline retail. In addition, they expect that some of these will become a more permanent part of the post-pandemic's new normal.

The semiconductor industry will be a key driver in creating a new-normal society. Considering the huge amount of investment in the semiconductor industry from not only East Asia but also the USA and Europe, the change will be accelerated more rapidly as we estimate. CMP is one of the strongest manufacturing processes to realize next-generation devices, which will be necessary in the new-normal society.

Figure 19 shows research topics of the papers covered in this review. From the Sustainability perspective, research on the environmental load of CMPs has been done in part in evaluating the overall semiconductor process. About $38 \%$ of the references in this review were on CMP wastewater treatment, and 23\% were on CMP slurry. The rest of the research was also on CMP consumables and system improvements (Fig. 20).

The future of CMP technology can be summarized with three key words: expansion, digitalization, and sustainability. First, its application is broadly expanding to highly integrated chips, three-dimensional microelectromechanical systems (MEMS), fan-out panel level packaging (FOPLP), and defect-free substrates. CMP can remove
Table 3 Hybrid CMP systems and their methods

\begin{tabular}{llc}
\hline System & Method & References \\
\hline Bell-jar type CMP & Control of ambient pressure and gas & {$[106]$} \\
P-CVM \& CMP & Combination of P-CVM and CMP & {$[108]$} \\
Electrolytic CMP & Electrolytic ionization of CMP slurry & {$[108]$} \\
Hybrid CMP slurry supply system & Ionization and atomization of CMP slurry & {$[109]$} \\
Photoelectrochemical planarization & Activation of OH radical & {$[110-113]$} \\
\hline
\end{tabular}


Fig. 19 Research topics of references in this review

\section{STUDIES ON SUSTAINABLE CMP IN THIS REVIEW}

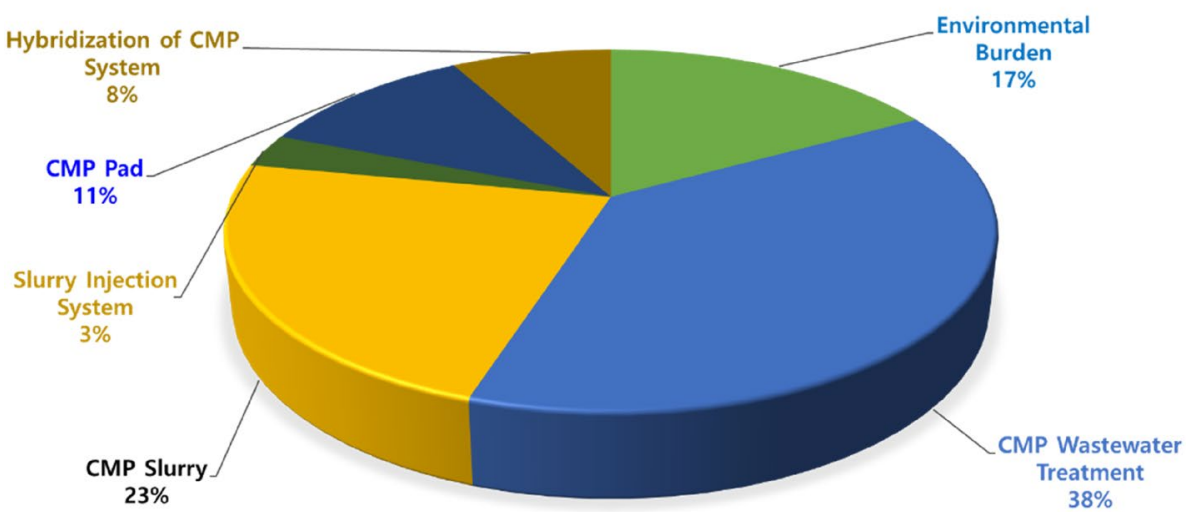

\section{Expansion}

- 3-D MEMS

- FOPLP

- Defect-free substrate

- Application to various materials

- Application to other fields

\section{Future of CMP}

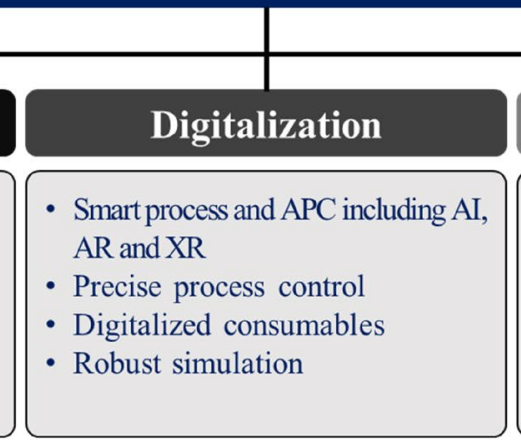

\begin{tabular}{|l|} 
Sustainability \\
- Minimization of the usage of \\
CMP consumables \\
- Improvement of energy efficiency of \\
CMP system \\
- Reduction of process time and \\
improvement of throughput
\end{tabular}

Fig. 20 Summary of the future of CMP

more than 40 types of materials and find solutions for all types of materials in the near future. In addition, electrochemical mechanisms in CMP technology are expected to be applied not only to semiconductors and displays that have been traditionally applied, but also to other fields such as maskless electrochemical texturing [114, 115]. The second issue for future CMP is digitalization of a smart process. For more accurate and precise process control, we require digitalized consumables, such as a micropatterned pad without unnecessary conditioning, robust simulation, and automatic process control (APC). The CMP system will be integrated using artificial intelligence (AI) and extended reality (XR) for acquiring more robust APCs. Finally, as discussed in this paper, sustainability will be a hot issue to reduce environmental burden by minimizing the usage of CMP consumables, reducing process time, improving energy efficiency of CMP system, and improving throughput. In the future of CMP technology facing global environmental regulations, sustainability approaches are expected to be indispensable and should proceed with technology expansion and digitalization.
Acknowledgements This work was supported by the Dong-A University research fund.

\section{References}

1. Lee, H. S., \& Jeong, H. D. (2019). Chemical and mechanical balance in polishing of electronic materials for defect-free surfaces. CIRP Annals, 58(1), 485-490. https://doi.org/10.1016/j. cirp.2009.03.115

2. Ein-Eli, Y., \& Starosvetsky, D. (2007). Review on copper chemical-mechanical polishing (CMP) and post-CMP cleaning in ultra large system integrated (ULSI)-An electrochemical perspective. Electrochimica Acta, 52(5), 1825-1838. https://doi.org/10. 1016/j.electacta.2006.07.039

3. Krishnan, M., Nalaskowski, J. W., \& Cook, L. M. (2010). Chemical mechanical planarization: Slurry chemistry, materials, and mechanisms. Chemical Reviews, 110(1), 178-204. https://doi. org/10.1021/cr900170z

4. Lee, H., Lee, D., \& Jeong, H. (2016). Mechanical aspects of the chemical mechanical polishing process: A review. International Journal of Precision Engineering and Manufacturing, 17(4), 525-536. https://doi.org/10.1007/s12541-016-0066-0

5. Lee, D., Lee, H., \& Jeong, H. (2016). Slurry components in metal chemical mechanical planarization (CMP) process: A 
review. International Journal of Precision Engineering and Manufacturing, 17(12), 1751-1762. https://doi.org/10.1007/ s12541-016-0201-y

6. Lee, H., \& Lee, S. (2017). Investigation of pad wear in CMP with swing-arm conditioning and uniformity of material removal. Precision Engineering, 49, 85-91. https://doi.org/10.1016/j.preci sioneng.2017.01.015

7. Chang, S.-H. (2005). A dishing model for STI CMP Process. Microelectronic Engineering, 82(2), 136-142. https://doi.org/10. 1016/j.mee.2005.07.002

8. Hwee, L. L., Balakumar, S., Mahadevan, S., Sheng, Z. M., See, A., Rahman, M., \& Senthikumar, A. (2001). Dishing and nitride erosion of STI-CMP for different integration schemes. Journal of Electronic Materials, 30, 1478-1482. https://doi.org/10.1007/ s11664-001-0161-5

9. Li, S., Gaudet, G., \& Nair, J. (2013). ILD CMP with silica abrasive particles: effect of pore size of cmp pad on removal rate profiles. ECS Journal of Solid State Science and Technology, 2(3), P97-P103. https://doi.org/10.1149/2.020303jss

10. Fayolle, M., Sicurani, E., \& Morand, Y. (1997). W CMP process integration: Consumables evaluation-electrical results and end point detection. Microelectronic Engineering, 37-38, 347-352. https://doi.org/10.1016/S0167-9317(97)00132-9

11. Lee, W.-S., Kim, S.-Y., Seo, Y.-J., \& Lee, J.-K. (2001). An optimization of tungsten plug chemical mechanical polishing (CMP) using different consumables. Journal of Materials Science: Materials in Electronics, 12, 63-68. https://doi.org/10.1023/A: 1011276830620

12. Hu, Z.-J., Qu, X.-P., Lin, H., Huang, R.-D., Ge, X.-C., Li, M., Chen, S.-M., \& Zhao, Y.-H. (2019). Cu CMP process development and characterization of $\mathrm{Cu}$ dishing with $1.8 \mu \mathrm{m} \mathrm{Cu}$ pad and $3.6 \mu \mathrm{m}$ pitch in $\mathrm{Cu} / \mathrm{SiO} 2$ hybrid bonding. Japanese Journal of Applied Physics, 58, SHHC01. https://doi.org/10.7567/13474065/ab17c4

13. Lee, H. (2018). Tribology research trends in chemical mechanical polishing (CMP) process. Tribology and Lubricants, 34(3), 115-122. https://doi.org/10.9725/kts.2018.34.3.115

14. Lee, H., \& Sung, I.-H. (2019). Chemical mechanical polishing: a selective review of $R \& D$ trends in abrasive particle behaviors and wafer materials. Tribology and Lubricants, 35(5), 274-285. https://doi.org/10.9725/kts.2019.35.5.274

15. Krishnan, N., Boyd, S., Rosales, J., Dornfeld, D., Raoux, S., \& Smati, R. (2004). Using a hybrid approach to evaluate semiconductor life cycle environmental issues: A case study in interconnect module impacts. IEEE International Symposium on Electronics and the Environment. https://doi.org/10.1109/isee.2004. 1299693

16. Hendrickson, C., Horvath, A., Joshi, S., \& Lave, L. (1998). Economic input-output models for environmental life-cycle assessment. Environmental Science and Technology, 32(7), 184A-191A. https://doi.org/10.1021/es983471i

17. Murphy, C. F., Kenic, G. A., Allen, D. T., Laurent, J.-P., \& Dyer, D. E. (2003). Development of parametric material, energy, and emission inventories for wafer fabrication in the semiconductor industry. Environmental Science and Technology, 37(23), 5373-5382. https://doi.org/10.1021/es034434g

18. Krishnan, N., Boyd, S., Somani, A., Raoux, S., Clark, D., \& Dornfeld, D. (2008). A hybrid life cycle inventory of nano-scale semiconductor manufacturing. Environmental Science and Technology, 42(8), 3069-3075. https://doi.org/10.1021/es071174k

19. Corlett, G. (2000). Targeting water use for chemical mechanical polishing. Solid State Technology, 43(6), 201-202.

20. Yang, G. C. C. (2002). CMP wastewater management using the concepts of design for environment. Environmental Progress, 21(1), 57-62. https://doi.org/10.1002/ep.670210113
21. Lo, R., \& Lo, S.-L. (2004). A pilot plant study using ceramic membrane microfiltration, carbon adsorption and reverse osmosis to treat CMP (chemical mechanical polishing) wastewater. Water Supply, 4(1), 111-118. https://doi.org/10.2166/ws.2004.0013

22. Lee, H., Park, S., \& Jeong, H. (2013). Evaluation of environmental impacts during chemical mechanical polishing (CMP) for sustainable manufacturing. Journal of Mechanical Science and Technology, 27(2), 511-518. https://doi.org/10.1007/ s12206-012-1241-6

23. Korea Power Exchange, Greenhouse gas emissions, Retrieved May 4, 2021 from https://www.kpx.or.kr/www/contents.do?key= 222.

24. Passmann, H., \& Joergensen, P. (2001). Energy consumption model for semiconductor manufacturing industry. MSC Thesis, Norweigian University of Science and Technology, February 2001.

25. Boyd, S. B., Horvath, A., \& Dornfeld, D. A. (2010). Supplementary data for 'Life-cycle assessment of computational logic produced from 1995 through 2010.' Environmental Research Letters, 5(1), 014011. https://doi.org/10.1088/1748-9326/5/1/ 014011

26. Kim, S., \& Overcash, M. (2003). Energy in chemical manufacturing processes: Gate-to-gate information for life cycle assessment. Journal of Chemical Technology and Biotechnology, 78(8), 995-1005. https://doi.org/10.1002/jctb.821

27. Lee, H., Dornfeld, D. A., \& Jeong, H. (2014). Mathematical model-based evaluation methodology for environmental burden of chemical mechanical planarization process. International Journal of Precision Engineering and Manufacturing-Green Technology, 1(1), 11-15. https://doi.org/10.1007/ s40684-014-0002-7

28. Wang, Y., Zhao, Y. W., \& Gu, J. (2007). A new nonlinear-microcontact model for single particle in the chemical-mechanical polishing with soft pad. Journal of Materials Processing Technology, 183(2-3), 374-379. https://doi.org/10.1016/j.jmatprotec. 2006.10.030

29. Lee, H., \& Jeong, H. (2011). A wafer-scale material removal rate profile model for copper chemical mechanical planarization. International Journal of Machine Tools and Manufacture, 51(5), 395-403. https://doi.org/10.1016/j.ijmachtools.2011.01.007

30. Roover, D., Emami-Naeini, A., \& Ebert, J. L. (2004). Modelbased control for chemical-mechanical planarization (CMP). Proceedings of the American Control Conference, 5, 3922-3929. https://doi.org/10.23919/ACC.2004.1383922

31. Lee, H. (2017). Environmental impact of concentration of slurry components in thick copper CMP. International Journal of Precision Engineering and Manufacturing-Green Technology, 4(1), 13-18. https://doi.org/10.1007/s40684-017-0002-5

32. Zhang, Z., Wang, B., Guo, D., Kang, R., \& Zhang, B. (2016). A novel approach of chemical mechanical polishing using environment-friendly slurry for mercury cadmium telluride semiconductors. Scientific Reports, 6, 22466. https://doi.org/10.1038/srep2 2466

33. Oliver, M. R. (2004). Chemical-mechanical planarization of semiconductor materials. Springer-Verlag.

34. Li, S. H., \& Miller, R. O. (2000). Chemical mechanical polishing in semiconductor processing. Academic Press.

35. Yin, T., Doi, T., Kurokawa, S., Ohnishi, O., Yamazaki, T., Wang, Z., \& Tan, Z. (2012). The effects of strong oxidizing slurry and processing atmosphere on double-sided CMP of $\mathrm{SiC}$ wafer. Advanced Materials Research, 591-593, 1131-1134. https://doi. org/10.4028/www.scientific.net/AMR.591-593.1131

36. Li, Z., Ina, K., Lefevre, P., Koshiyama, I., \& Philipossian, A. (2005). Determining the effects of slurry surfactant, abrasive size, and abrasive content on the tribology and kinetics of 
copper CMP. Journal of The Electrochemical Society, 152(4), G299-G304. https://doi.org/10.1149/1.1869974

37. Neirynck, J. M., Yang, G.-R., Murarka, S. P., \& Gutmann, R. J. (1996). The addition of surfactant to slurry for polymer CMP: Effects on polymer surface, removal rate and underlying $\mathrm{Cu}$. Thin Solid Films, 290-291, 447-452. https://doi.org/10.1016/ S0040-6090(96)09033-5

38. Surisetty, C. V. V. S., Goonetilleke, P. C., Roy, D., \& Babu, S. V. (2008). Dissolution inhibition in Cu-CMP using dodecylbenzene-sulfonic acid surfactant with oxalic acid and glycine as complexing agents. Journal of The Electrochemical Society, 155(12), H971-H980. https://doi.org/10.1149/1.2987791

39. Miao, Y., Wang, S., Wang, C., Liu, Y., Sun, M., \& Chen, Y. (2014). Effect of chelating agent on benzotriazole removal during post copper chemical mechanical polishing cleaning. Microelectronic Engineering, 130, 18-23. https://doi.org/10. 1016/j.mee.2014.08.012

40. Zhang, K., Niu, X., Wang, C., Wang, J., Yin, D., \& Wang, R. (2018). Effect of chelating agent and ammonium dodecyl sulfate on the interfacial behavior of copper CMP for GLSI. ECS Journal of Solid State Science and Technology, 7(9), P509P517. https://doi.org/10.1149/2.0231809jss

41. Li, Y., Liu, Y., Niu, X., Bu, X., Li, H., Tang, J., \& Fan, S. (2014). Application of a macromolecular chelating agent in chemical mechanical polishing of copper film under the condition of low pressure and low abrasive concentration. Journal of Semiconductors, 35(1), 016001. https://doi.org/10.1088/16744926/35/1/016001

42. Ryu, H.-Y., Cho, B.-J., Yerriboina, N. P., Lee, C.-H., Hwang, J.-K., Hamada, S., Wada, Y., Hiyama, H., \& Park, J.-G. (2019). Selection and optimization of corrosion inhibitors for improved $\mathrm{Cu}$ CMP and post-Cu CMP cleaning. ECS Journal of Solid State Science and Technology, 8(5), P3058-P3062. https://doi. org/10.1149/2.0101905jss

43. Bi, X., Reed, R., \& Westerhoff, P. (2015). Control of nanomaterials used in chemical mechanical polishing/planarization slurries during on-site industrial and municipal biological wastewater treatment. In M. Baalousha \& J. R. Lead (Eds.), Characterization of nanomaterials in complex environmental and biological media (1st ed., pp. 247-265). Elsevier.

44. MARKETS AND MARKETS, Cerium Oxide Nanoparticles Market by Form (Dispersion and Powder), Application (Chemical Mechanical Planarization, Catalyst, Biomedical, Energy), and Region (North America, APAC, Europe, and RoW)-Global Forecast to 2022. Retrieved May 4, 2021 from https://www. marketsandmarkets.com/Market-Reports/cerium-oxide-nanop article-market-190394869.html.

45. Kuan, W.-H., \& Hu, C.-Y. (2009). Chemical evidences for the optimal coagulant dosage and $\mathrm{pH}$ adjustment of silica removal from chemical mechanical polishing (CMP) wastewater. Colloids and Surfaces A, 342(1-3), 1-7. https://doi.org/10.1016/j. colsurfa.2009.03.019

46. Liu, J. C., \& Lien, C. Y. (2006). Dissolved air flotation of polishing wastewater from semiconductor manufacturer. Water Science and Technology, 53(7), 133-140. https://doi.org/10. 2166/wst.2006.217

47. Tsai, J.-C., Kumar, M., Chen, S.-Y., \& Lin, J.-G. (2007). Nanobubble flotation technology with coagulation process for the cost-effective treatment of chemical mechanical polishing wastewater. Separation and Purification Technology, 58(1), 61-67. https://doi.org/10.1016/j.seppur.2007.07.022

48. Lien, C. Y., \& Liu, J. C. (2006). Treatment of polishing wastewater from semiconductor manufacturer by dispersed air flotation. Journal of Environmental Engineering, 132(1), 51-57. https://doi.org/10.1061/(ASCE)0733-9372(2006)132:1(51)
49. Lin, S. H., \& Yang, C. R. (2004). Chemical and physical treatments of chemical mechanical polishing wastewater from semiconductor fabrication. Journal of Hazardous Materials, 108(1), 103-109. https://doi.org/10.1016/j.jhazmat.2004.01.014

50. Browne, F. L. S. S., Krygier, V., \& O’Sullivan, J. (March 1999). Treating wastewater from CMP using ultrafiltration. MICRO.

51. Juang, L.-C., Tseng, D.-H., Lin, H.-Y., Lee, C.-K., \& Liang, T.-M. (2008). Treatment of chemical mechanical polishing wastewater for water reuse by ultrafiltration and reverse osmosis separation. Environmental Engineering Science, 25(7), 10911098. https://doi.org/10.1089/ees.2007.0056

52. Sanusi, N. F. A. M., Yusoff, M. H. M., Seng, S. B., Marzuki, M. S., \& Abdullah, A. Z. (2018). Ultrafiltration based on various polymeric membranes for recovery of spent tungsten slurry for reuse in chemical mechanical polishing process. Journal of Membrane Science, 548, 232-238. https://doi.org/10.1016/j.memsci. 2017.11.034

53. Mollah, M. Y. A., Schennach, R., Parga, J. R., \& Cocke, D. L. (2001). Electrocoagulation (EC)-science and applications. Journal of Hazardous Materials, 84(1), 29-41. https://doi.org/10. 1016/S0304-3894(01)00176-5

54. Szynkarczuk, J., Kan, J., \& Hassan, T. A. T. (1994). Electrochemical coagulation of clay suspensions. Clays and Clay Minerals, 42, 667-673. https://doi.org/10.1346/CCMN.1994.0420602

55. Matteson, M. J., Dobson, R. L., Glenn, R. W., Jr., Kukunoor, N. S., Waits, W. H., III., \& Clayfield, E. J. (1995). Electrocoagulation and separation of aqueous suspensions of ultrafine particles. Colloids and Surfaces A, 104(1), 101-109. https://doi.org/10. 1016/0927-7757(95)03259-G

56. Donnin, J. C., Kan, J., Hassan, T. A., \& Kar, K. L. (1994). The operating cost of electrocoagulation. The Canadian Journal of Chemical Engineering, 72(6), 1007-1012. https://doi.org/10. 1002/cjce.5450720610

57. Belongia, B. M., Haworth, P. D., Baygents, J. C., \& Raghavan, S. (1999). Treatment of alumina and silica chemical mechanical polishing waste by electrodecantation and electrocoagulation. Journal of The Electrochemical Society, 146(11), 4124-4130. https://doi.org/10.1149/1.1392602

58. Den, W., \& Huang, C. (2005). Electrocoagulation for removal of silica nano-particles from chemical-mechanical-planarization wastewater. Colloids and Surfaces A, 254(1-3), 81-89. https:// doi.org/10.1016/j.colsurfa.2004.11.026

59. Lai, C. L., \& Lin, S. H. (2003). Electrocoagulation of chemical mechanical polishing (CMP) wastewater from semiconductor fabrication. Chemical Engineering Journal, 95(1-3), 205-211. https://doi.org/10.1016/S1385-8947(03)00106-2

60. Lai, C. L., \& Lin, S. H. (2004). Treatment of chemical mechanical polishing wastewater by electrocoagulation: System performances and sludge settling characteristics. Chemosphere, 54(3), 235-242. https://doi.org/10.1016/j.chemosphere.2003.08.014

61. Drouiche, N., Ghaffour, N., Lounici, H., \& Mameri, M. (2007). Electrocoagulation of chemical mechanical polishing wastewater. Desalination, 214(1-3), 31-37. https://doi.org/10.1016/j.desal. 2006.11.009

62. Stamberger, P. (1946). The method of purifying and concentrating colloidal dispersions by electrodecantation. Journal of Colloid Science, 1(1), 93-103. https://doi.org/10.1016/00958522(46)90009-8

63. Weigert, T., Altmann, J., \& Ripperger, S. (1999). Crossflow electrofiltration in pilot scale. Journal of Membrane Science, 159, 253-262. https://doi.org/10.1016/S0376-7388(99)00068-X

64. Sung, M., Huang, C. P., Weng, Y.-H., Lin, Y.-T., \& Li, K.-C. (2007). Enhancing the separation of nano-sized particles in lowsalt suspensions by electrically assisted cross-flow filtration. Separation and Purification Technology, 54, 170-177. https:// doi.org/10.1016/j.seppur.2006.09.001 
65. Yang, G. C. C., Yang, T.-Y., \& Tsai, S.-H. (2003). Crossflow electro-microfiltration of oxide-CMP wastewater. Water Research, 37(4), 785-792. https://doi.org/10.1016/S00431354(02)00388-3

66. Yang, G. C. C., \& Yang, T.-Y. (2004). Reclamation of high quality water from treating CMP wastewater by novel crossflow electrofiltration/electrodialysis process. Journal of Membrane Science, 233(1-2), 151-159. https://doi.org/10.1016/j.memsci. 2004.01.011

67. Yang, G. C. C., \& Li, C.-J. (2008). Tubular $\mathrm{TiO}_{2} / \mathrm{Al}_{2} \mathrm{O}_{3}$ composite membranes: Preparation, characterization, and performance in electrofiltration of oxide-CMP wastewater. Desalilnation, 234(1-3), 354-361. https://doi.org/10.1016/j.desal.2007.09.104

68. Li, Y. (2008). Microelectronic applications of chemical mechanical planarization. Wiley \& Sons Inc.

69. Lee, T.-C., Lin, K.-L., Su, X.-W., \& Lin, K.-K. (2012). Recycling CMP sludge as a resource in concrete. Construction and Building Materials, 30, 243-251. https://doi.org/10.1016/j.conbuildmat. 2011.11.019

70. Penta, N. K. (2016). Abrasive-free and ultra-low abrasive chemical mechanical polishing (CMP) processes. In S. Babu (Ed.), Advances in chemical mechanical planarization (CMP) (1st ed., pp. 213-227). Woodhead Publishing.

71. Liu, X., Liua, Y., Liang, Y., Liu, H., Hu, Y., \& Gao, B. (2011). Optimization of slurry components for a copper chemical mechanical polishing at low down pressure using response surface methodology. Microelectronic Engineering, 88(1), 99-104. https://doi.org/10.1016/j.mee.2010.09.007

72. Jindal, A., Hegde, S., \& Babu, S. V. (2002). Chemical mechanical polishing using mixed abrasive slurries. Electrochemical and Solid-State Letters, 5(7), G48-G50. https://doi.org/10.1149/1. 1479297

73. Seo, Y.-J., \& Lee, W.-S. (2004). Chemical mechanical polishing of $\mathrm{Ba}_{0.6} \mathrm{Sr}_{0.4} \mathrm{TiO}_{3}$ film prepared by sol-gel method. Microelectronic Engineering, 75(2), 149-154. https://doi.org/10.1016/j. mee.2004.03.086

74. Park, S.-W., Seo, Y.-J., \& Lee, W.-S. (2008). A study on the chemical mechanical polishing of oxide film using a zirconia $\left(\mathrm{ZrO}_{2}\right)$-mixed abrasive slurry (MAS). Microelectronic Engineering, 85(4), 682-688. https://doi.org/10.1016/j.mee.2007.12.049

75. Lee, H., \& Jeong, H. (2015). Analysis of removal mechanism on oxide CMP using mixed abrasive slurry. International Journal of Precision Engineering and Manufacturing, 16(3), 307-603. https://doi.org/10.1007/s12541-015-0081-6

76. Lee, H., Lee, D., Kim, M., \& Jeong, H. (2017). Effect of mixing ratio of non-spherical particles in colloidal silica slurry on oxide CMP. International Journal of Precision Engineering and Manufacturing, 18(10), 1333-1338. https://doi.org/10.1007/ s12541-017-0158-5

77. Lu, Z., Lee, S.-H., Gorantla, V. R. K., Babu, S. V., \& Matijevic, E. (2003). Effects of mixed abrasives in chemical mechanical polishing of oxide films. Journal of Materials Research, 18(10), 2323-2330. https://doi.org/10.1557/JMR.2003.0326

78. Lee, Y., Seo, Y.-J., \& Jeong, H. (2012). Evaluation of oxidechemical mechanical polishing characteristics using ceria-mixed abrasive slurry. Electronic Materials Letters, 8(5), 523-528. https://doi.org/10.1007/s13391-012-2056-4

79. Lee, Y., Seo, Y.-J., Lee, H., \& Jeong, H. (2016). Effect of diluted colloidal silica slurry mixed with ceria abrasives on CMP characteristic. International Journal of Precision Engineering and Manufacturing-Green Technology, 3(1), 13-17. https://doi.org/ 10.1007/s40684-016-0002-x

80. Lee, H. S., Kim, D. I., An, J. H., Lee, H. J., Kim, K. H., \& Jeong, H. (2010). Hybrid polishing mechanism of single crystal $\mathrm{SiC}$ using mixed abrasive slurry (MAS). CIRP Annals, 59(1), 333-336. https://doi.org/10.1016/j.cirp.2010.03.114
81. Li, S., Sun, L., Tsai, S., Liu, F. Q., \& Chen, L. (2001). A low cost and residue-free abrasive-free copper cmp process with low dishing, erosion and oxide loss. Proceedings of the IEEE 2001 International Interconnect Technology Conference. https://doi.org/10.1109/IITC.2001.930039

82. Amanokura, J., Mabuchi, K., Sakurada, T., Nomura, Y., \& Habiro, M. (2007). newly developed abrasive-free copper CMP slurry based on electrochemical analysis. MRS Online Proceedings Library (OPL), Volume 991. https://doi.org/10. 1557/PROC-0991-C03-01

83. Kamigata, Y., Kurata, Y., Masuda, K., Amanokura, J., Yoshida, M., \& Hanazono, M. (2001). Why abrasive free $\mathrm{Cu}$ slurry is promising? MRS Online Rroceedings Library (OPL), Volume 671. https://doi.org/10.1557/PROC-671-M1.3

84. Ramakrishnan, S., Jankam, S. V. S. B., Patri, U. B., Roy, D., \& Babu, S. V. (2007). Comparison of dicarboxylic acids as complexing agents for abrasive-free chemical mechanical planarization of copper. Microelectronic Engineering, 84(1), 80-86. https://doi.org/10.1016/j.mee.2006.08.011

85. Yang, G., He, P., \& Qu, X.-P. (2018). Inhibition effect of glycine on molybdenum corrosion furing CMP in alkaline $\mathrm{H}_{2} \mathrm{O}_{2}$ based abrasive free slurry. Applied Surface Science, 427, 148155. https://doi.org/10.1016/j.apsusc.2017.08.140

86. Hara, H., Sano, Y., Mimura, H., Arima, K., Kubota, A., Yagi, K., Murata, J., \& Yamauch, K. (2006). Novel abrasive-free planarization of $4 \mathrm{H}-\mathrm{SiC}$ (0001) using Catalyst. Journal of Electronic Materials, 35(8), L11-L14. https://doi.org/10.1007/ s11664-006-0218-6

87. Pandija, S., Roy, D., \& Babu, S. V. (2007). Chemical mechanical planarization of copper using abrasive-free solutions of oxalic acid and hydrogen peroxide. Materials Chemistry and Physics, 102(2-3), 144-151. https://doi.org/10.1016/j.match emphys.2006.11.015

88. Jeong, H., Kim, H., Lee, S., \& Dornfeld, D. (2006). Multisensor monitoring system in CMP for correlations with process issues. CIRP Annals, 55(1), 325-328. https://doi.org/10.1016/ S0007-8506(07)60427-2

89. Bibby, T., Adams, J., \& Holland, K. (1999). Optical endpoint detection for chemical mechanical planarization. Journal of Vacuum Science and Technology B, 17, 2378-2384. https:// doi.org/10.1116/1.590922

90. Suzuki, N., Hashimoto, Y., Yasuda, H., Yamaki, S., \& Mochizuki, Y. (2017). Prediction of polishing pressure distribution in CMP process with airbag type wafer carrier. CIRP annals, 66(1), 329-332. https://doi.org/10.1016/j.cirp.2017.04.088.

91. Park, Y., Lee, H., Park, S., \& Jeong, H. (2013). Effect of contact angle between retaining ring and polishing pad on material removal uniformity in CMP process. International Journal of Precision Engineering and Manufacturing, 14(9), 1513-1518. https://doi.org/10.1007/s12541-013-0204-X

92. Park, J., Han, J., \& Kim, C. (2020). A study on the influence of the cross-sectional shape of the metal-inserted retainer ring and the pressure distribution from the multi-zone carrier head to increase the wafer yield. Applied Sciences, 10(23), 8362. https://doi.org/10.3390/app10238362

93. Lee, D., Lee, H., \& Jeong, H. (2015). The effects of a spray slurry nozzle on copper CMP for reduction in slurry consumption. Journal of Mechanical Science and Technology, 29(12), 5057-5062. https://doi.org/10.1007/s12206-015-1101-2

94. Liao, X., Sampurno, Y., Zhuang, Y., \& Philipossian, A. (2012). Effect of slurry application/injection schemes on slurry availability during chemical mechanical planarization (CMP). Electrochemical and Solid-State Letters, 15(4), H118-H122. https://doi.org/10.1149/2.009205esl 
95. Borucki, L. (2016). A novel slurry injection system for CMP. In $\mathrm{S}$. Babu (Ed.), Advances in chemical mechanical planarization (CMP) (1st ed., pp. 397-415). Woodhead Publishing.

96. Industry Research, Global CMP Pads Sales Market Report 2021, Retrieved May 4, 2021 from https://www.industryre search.co/global-cmp-pads-sales-market-17622105.

97. Lee, W.-J., Park, H.-S., \& Shin, H.-C. (2009). Enhancement of CMP pad lifetime for shallow trench isolation process using profile simulation. Current Applied Physics, 9(1), S134-S137. https://doi.org/10.1016/j.cap.2008.08.017

98. Huey, S., Mear, S. T., Wang, Y., Jin, R. R., Ceresi, J., Freeman, P., Johnson, D., Vo, T., \& Eppert, S. (1999). Technological breakthrough in pad life improvement and its impact on CMP CoC. Annual IEEE/SEMI Advanced Semiconductor Manufacturing Conference and Workshop. https://doi.org/10. 1109/ASMC.1999.798181

99. Tseng, W.-T., Mohan, K., Hull, R., Hagan, J., Truong, C., Lehuu, D. K., \& Muradian, D. (2016). A microreplicated pad for tungsten chemical-mechanical planarization. ECS Journal of Solid State Science and Technology, 5(9), P546-P552. https://doi.org/10.1149/2.0391609jss

100. Menk, G. E., Dhandapani, S., Garretson, C. C., \& Chang, S.-S. (2010). Real-time control system for improved CMP pad profiles. MRS Online Proceedings Library (OPL), Volume 1249. https://doi.org/10.1557/PROC-1249-E02-02

101. Togawa, T., Namiki, K., \& Yamaki, S. (2014). Method and apparatus for dressing polishing pad, profile mesuring method, substrate polishinbg apparatus, and substrate polishing method. US8870625B2.

102. Khanna, A. J., Jawali, P., Redfield, D., Kakireddy, R., Chockalingam, A., Benvegnu, D., Yang, M., Rozo, S., Fung, J., Cornejo, M., Abramson, I., Yamamura, M., Yuan, Z., \& Bajaj, R. (2019). Methodology for pad conditioning sweep optimization for advanced nodes. Microelectronic Engineering, 216(15), 111101. https://doi.org/10.1016/j.mee.2019.111101

103. Kim, Y., \& Kang, S. (2011). Novel CVD diamond-coated conditioner for improved performance in CMP processes. International Journal of Machine Tools and Manufacture, 51(6), 565-568. https://doi.org/10.1016/j.ijmachtools.2011.02.008

104. Chen, C.-C., Li, J.-C., Liao, W.-C., Ciou, Y.-J., \& Chen, C.-C. (2021). Dynamic pad surface metrology monitoring by swingarm chromatic confocal system. Applied Sciences, 11(1), 179. https://doi.org/10.3390/app11010179

105. Son, J., \& Lee, H. (2021). Contact-area-changeable CMP conditioning for enhancing pad lifetime. Applied. Sciences, 11(8), 3521. https://doi.org/10.3390/app11083521

106. Kurokawa, S., Doi, T., Ohnishi, O., Yamazaki, T., Tan, Z., \& Yin, T. (2013). Characteristics in SiC-CMP using $\mathrm{MnO}_{2}$ slurry with strong oxidant under different atmospheric conditions. MRS Online Proceedings Library (OPL), Volume 1560. https:// doi.org/10.1557/opl.2013.903

107. Doi, T. K., Sano, Y., Kurowaka, S., Aida, H., Ohnishi, O., Uneda, M., \& Ohyama, K. (2014). Novel chemical mechanical polishing/plasma-chemical vaporization machining (CMP/PCVM) combined processing of hard-to-process crystals based on innovative concepts. Sensor and Materials, 26(6), 403-415. https://doi.org/10.18494/SAM.2014.978

108. Lee, D., Lee, H., Jeong, S., Yuh, M., \& Jeong, H. (2019). Surface activation by electrolytically ionized slurry during $\mathrm{Cu}$ CMP. ECS J. Solid State Sci. Technol., 8(5), P3053-P3057. https://doi.org/10.1149/2.0091905jss

109. Jo, H., Lee, D. S., Jeong, S. H., Lee, H. S., \& Jeong, H. D. (2021). Hybrid CMP slurry supply system using ionization and atomization. Applied Sciences, 11(5), 2217. https://doi.org/10. 3390/app11052217
110. Li, W., Ma, M., \& Hu, B. (2001). A study on Surface quality of GaN with CMP polishing process. Advanced Materials Research, 291-294, 1764-1767. https://doi.org/10.4028/www. scientific.net/AMR.291-294.1764

111. Murata, J., Kubota, A., Yagi, K., Sano, Y., Hara, H., Arima, J., Okamoto, T., Mimura, H., \& Yamauchi, K. (2008). Chemical planarization of $\mathrm{GaN}$ using hydroxyl radicals generated on a catalyst plate in $\mathrm{H}_{2} \mathrm{O}_{2}$ solution. Journal of Crystal Growth, 310(7-9), 1637-1641. https://doi.org/10.1016/j.jcrysgro.2007. 11.093

112. Wang, J., Wang, T., Pan, G., \& Lu, X. (2015). Mechanism of GaN CMP Based on $\mathrm{H}_{2} \mathrm{O}_{2}$ Slurry Combined with UV Light. ECS Journal of Solid State Science and Technology, 4(3), P112-P117. https://doi.org/10.1149/2.0191503jss

113. Yuan, Z., He, Y., Sun, X., \& Wen, Q. (2018). UV-TiO 2 photocatalysis assisted chemical mechanical polishing $4 \mathrm{H}-\mathrm{SiC}$ wafer. Materials and Manufacturing Processes, 33(11), 1214-1222. https://doi.org/10.1080/10426914.2017.1364855

114. Silva, L. R. R., \& Costa, H. L. (2017). Tribological behavior of gray cast iron textured by maskless electrochemical texturing. Wear, 376-377, 1601-1610. https://doi.org/10.1016/j.wear. 2017.01.028

115. Silva, L., \& Costa, H. (2017). Maskless electrochemical texturing of automotive cylinders. Materials Performance and Characterization, 6(2), 96-111. https://doi.org/10.1520/MPC20 160027

Publisher's Note Springer Nature remains neutral with regard to jurisdictional claims in published maps and institutional affiliations.

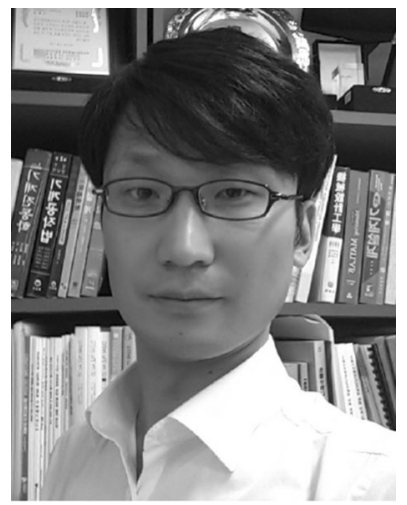

Hyunseop Lee is an Associate Professor at the Department of Mechanical Engineering as well as a director of Hybrid Precision Engineering Lab, Dong-A University, Busan, Korea. He received his B.S., M.S. and Ph.D. degrees in Mechanical Engineering from Pusan National University. From 2011 to 2012, he worked at UC Berkeley as a Post-Doc. Researcher. His research interests include chemical mechanical polishing (CMP), tribology, grinding, and abrasive fluidized bed

machining.

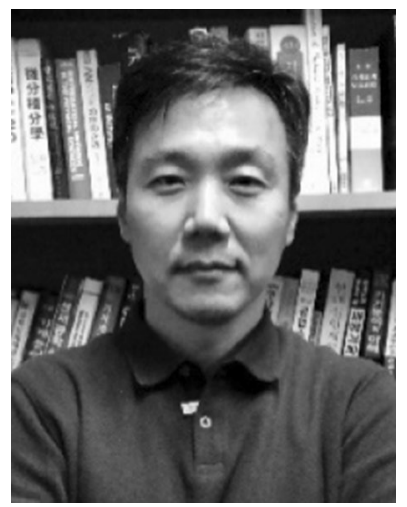

Hyoungjae Kim is currently a principal researcher at Korea Institute of Industrial Technology, Busan, Korea. He received his bachelor's, master's and doctoral degrees from Department of Mechanical Engineering, Pusan National University. His research interests include studies related to CMP equipment design, process control and consumables, and he is also interested in wafer manufacturing processes used in power devices. 


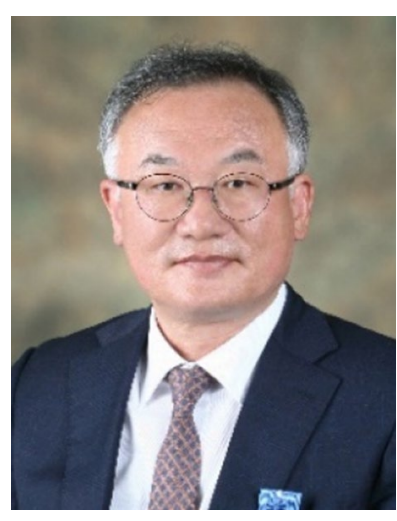

Haedo Jeong received B.S. degree from Pusan National University, Korea in 1987 and the M.S. degree and Ph.D. in mechanical engineering from KAIST, Korea in 1989 and from University of Tokyo, Japan in 1994, respectively. From 1989 to 1991, he worked at government research institutes of KIST and $\mathrm{KITECH}$, where he was responsible for abrasive machining process such as grinding and polishing. In 1994, he joined at Japanese government project with RIKEN and Fujikoshi machinery, Japan as a post-doc. researcher to develop a CMP equipment. From 1995, he is working as a professor in the school of mechanical engineering as well as a director of CMP Lab at Pusan National University. His research interests include wafering processes, chemical mechanical polishing and its post cleaning. He has authored more than 600 technical publications/presentations in the area of abrasive processing, 3D printing and CMP. 